NBER WORKING PAPER SERIES

CAPITAL TAXATION AND OWNERSHIP WHEN MARKETS ARE INCOMPLETE

\author{
Emmanuel Farhi \\ Working Paper 13390 \\ http://www.nber.org/papers/w13390 \\ NATIONAL BUREAU OF ECONOMIC RESEARCH \\ 1050 Massachusetts Avenue \\ Cambridge, MA 02138 \\ September 2007
}

My debt to my advisors Ricardo Caballero, George-Marios Angeletos and Ivan Werning cannot be overstated. For helpful discussions and insightful comments, I thank Daron Acemoglu, Abhijit Banerjee, Olivier Blanchard, V.V Chari, Xavier Gabaix, Mike Golosov, Patrick Kehoe, Narayana Kocherlakota, Guido Lorenzoni, Veronica Guerrieri, and seminar participants at the Minneapolis Fed, MIT, Chicago, Harvard, Princeton, Berkeley, Stanford, NYU, Columbia, Yale. The views expressed herein are those of the author(s) and do not necessarily reflect the views of the National Bureau of Economic Research.

(C) 2007 by Emmanuel Farhi. All rights reserved. Short sections of text, not to exceed two paragraphs, may be quoted without explicit permission provided that full credit, including $\odot$ notice, is given to the source. 
Capital Taxation and Ownership when Markets are Incomplete

Emmanuel Farhi

NBER Working Paper No. 13390

September 2007

JEL No. A1,E21,E22,E23,E6,E60,E62,E66,H21,H3,H31,H32,H6,H60,H61,H62

\begin{abstract}
$\underline{\text { ABSTRACT }}$
This paper analyzes the theoretical and quantitative implications of optimal capital taxation in the neoclassical growth model with aggregate shocks and incomplete markets. The model features a representative-agent economy with proportional taxes on labor and capital. I first consider the case that the only asset the government can trade is a real risk-free bond. Taxes on capital are set one period in advance, reflecting inertia in tax codes and ruling out replication of the complete markets allocation. Because capital income varies with the state of the economy, capital taxation provides a state contingent source of revenues. I thus identify a novel potential role for capital taxation as a risk sharing instrument between the government and private agents. However, this benefit must be weighted again the distortionary cost of capital taxation. For a baseline case, the optimal policy features a zero tax on capital. Moreover, numerical simulations show that the baseline case provides an excellent benchmark. I next allow the government to hold a non trivial position in capital. Capital ownership provides the same benefit or risk sharing but without the cost of tax distortions. In a variety of quantitative exercises, I show that capital ownership allows the government to realize about $90 \%$ of the welfare gains from moving to complete markets. Large positions are typically required for optimality. But smaller positions achieve substantial benefits. In a business-cycle simulation, I show that a $15 \%$ short equity position achieves over $40 \%$ of the welfare gains from completing markets.

Emmanuel Farhi

Harvard University

Department of Economics

Littauer Center

Cambridge, MA 02138

and NBER

efarhi@harvard.edu
\end{abstract}




\title{
Capital Taxation and Ownership when Markets are Incomplete*
}

\author{
Emmanuel Farhi \\ Harvard \\ efarhi@harvard.edu
}

August 26th, 2007.

\begin{abstract}
This paper analyzes the theoretical and quantitative implications of optimal capital taxation in the neoclassical growth model with aggregate shocks and incomplete markets. The model features a representative-agent economy with proportional taxes on labor and capital. I first consider the case that the only asset the government can trade is a real risk-free bond. Taxes on capital are set one period in advance, reflecting inertia in tax codes and ruling out replication of the complete markets allocation. Because capital income varies with the state of the economy, capital taxation provides a state contingent source of revenues. I thus identify a novel potential role for capital taxation as a risk sharing instrument between the government and private agents. However, this benefit must be weighted again the distortionary cost of capital taxation. For a baseline case, the optimal policy features a zero tax on capital. Moreover, numerical simulations show that the baseline case provides an excellent benchmark. I next allow the government to hold a non trivial position in capital. Capital ownership provides the same benefit or risk sharing but without the cost of tax distortions. In a variety of quantitative exercises, I show that capital ownership allows the government to realize about $90 \%$ of the welfare gains from moving to complete markets. Large positions are typically required for optimality. But smaller positions achieve substantial benefits. In a business-cycle simulation, I show that a $15 \%$ short equity position achieves over $40 \%$ of the welfare gains from completing markets.
\end{abstract}

\section{Introduction}

In this paper, I explore the issue of capital taxation and government ownership when fiscal expenditures and aggregate income are random, and the government can only trade a limited number of assets. Markets are incomplete, and hedging of the government budget is limited in scope. This

${ }^{*}$ My debt to my advisors Ricardo Caballero, George-Marios Angeletos and Ivan Werning cannot be overstated. For helpful discussions and insightful comments, I thank Daron Acemoglu, Abhijit Banerjee, Olivier Blanchard, V.V Chari, Xavier Gabaix, Mike Golosov, Patrick Kehoe, Narayana Kocherlakota, Guido Lorenzoni, Veronica Guerrieri, and seminar participants at the Minneapolis Fed, MIT, Chicago, Harvard, Princeton, Berkeley, Stanford, NYU, Columbia, Yale. 
creates a new potential role for capital taxation and ownership as risk sharing instruments between the government and private agents. In the model, capital taxation and capital ownership provide a state contingent source of revenues. For example, if the marginal product of capital is positively correlated with adverse shocks to the government budget, positive capital taxes, or a long position in the capital stock, might provide the government with a good hedging instrument.

I approach these issues by taking a minimal step away from the complete markets case: I consider the stochastic neoclassical growth model with homogenous consumers and a benevolent government facing fiscal expenditure shocks. I allow the government to trade a risk free bond, to levy fully state contingent linear taxes on labor, and to levy linear taxes on capital that are not fully state contingent. Specifically, I assume that taxes on capital are set one period in advance, at the time investment decisions are made. This assumption is meant to capture inertia in fiscal policy. With fully state contingent taxes on capital the government would be able to replicate the complete markets allocation, as shown by Judd (1992) and Chari, Christiano and Kehoe (1994). ${ }^{1}$ With a lag in capital taxes, the complete markets allocation is not achievable.

An important insight in this paper is that when contemplating the hedging consequences of a marginal increase in capital taxes, the government needs to take two effects into consideration. First is the direct effect in the form of increased revenues in proportion to the marginal product of capital. Second is an opposing indirect effect through the adjustment of capital: Lower capital accumulation reduces the revenues from labor and capital taxes. The hedging benefits of capital taxation depend only on the covariance of these two effects with the government's need for funds across states of the world on a given date. An important benchmark is the baseline case where the production function is Cobb Douglas and preferences are quasi-linear. I show in this case that taxes on capital should be set to zero from the first period on. With these specifications, the covariances of the direct and indirect effects with the government's need for funds exactly cancel out, leaving no role for capital taxes.

For general preferences, I show that optimal taxes on capital can be decomposed into two terms. The first "hedging" term - the only one present when preferences are quasi-linear - reflects the hedging role of capital taxes, and would be zero if markets were complete. The second "intertemporal" term corresponds to the motive for capital taxation when markets are complete: It might be optimal for the government to distort capital accumulation to smooth available resources in the economy across time. Echoing the result in the previous paragraph, I show that the hedging term is zero when the production function is Cobb Douglas. Regarding the intertemporal term, the optimal policy prescribes a one time capital tax (respectively subsidy) following a high (respectively low) government expenditure shock in order to reduce the variability of the net present value of labor tax surpluses across states.

\footnotetext{
${ }^{1}$ An intuition for this result can be given along the following lines: Since investment only reacts to average taxes on capital, the government can vary capital taxes across states while keeping the average constant, leaving investment in physical capital unaffected. This endows the government with enough degrees of freedom to perfectly shift the tax burden across states and to replicate the complete markets outcome as long as long as it can also trade a risk free bond.
} 
Numerical simulations show that the baseline case provides a good benchmark: the hedging term, while not theoretically zero, turns out to be negligible. Incomplete markets do not seem to make a case for using capital taxation as a hedging instrument. The intertemporal term is approximately zero mean. Its volatility decreases sharply with the period length.

In contrast to capital taxes, capital ownership may provide the government with a powerful hedging instrument. The reason is that unlike taxing, trading does not introduce additional distortions: The indirect effect on labor and capital tax bases arising with capital taxation is absent for capital trading. ${ }^{2}$ Indeed, when preferences are quasi-linear and the only disturbance in the economy takes the form of government expenditures shocks, I show that the government can perfectly approximate the complete markets allocation by taking a very large position in capital, counterbalanced by an equally large opposite position in the risk free bond.

Outside of this benchmark case, numerical simulations show that capital ownership allows to realize about $90 \%$ of the welfare gains from moving to complete markets. Government expenditure shocks tend to call for a long position, while productivity shocks typically require a short position. In business cycle simulations, productivity shocks dwarf government expenditure shocks as a source of variation in the government's budget, calling for a short position.

Optimality typically requires large position. The magnitude of the position decreases sharply with the period length. Moreover, smaller positions allow to reap substantial benefits: In a business cycle simulation with a five years period length, I show that a short position of $15 \%$ of the capital stock achieves more than $40 \%$ of the gains from completing markets.

I then characterize the optimal holding of capital by the government in a more general portfolio problem with additional assets. I derive the government's optimal liability structure in a unified framework, that I term the GCAPM - Government Capital Asset Pricing Model - and that resembles the CCAPM: Assets that covary with the government's need for funds command a lower expected return. I am able to explicitly derive the pricing kernel of the government. This can be used to price non-traded assets, and provides theoretical foundations for capital budgeting rules in public, non traded companies. ${ }^{3}$

\section{Related Literature.}

An extensive literature on capital taxation with complete markets has emerged from the celebrated zero long run capital tax result established by Chamley (1986) and Judd (1985). This paper adds to this literature by studying the case of incomplete markets.

Chamely (1986) and Judd (1985) showed that in all steady states of the economy, taxes on capital are optimally set to zero. Zhu (1992) proved a stochastic analog of the Chamley-Judd result: In every stochastic steady state of the neoclassical growth model, depending on the underlying parameters of the model, taxes on capital are either zero or take both signs with positive probability.

\footnotetext{
${ }^{2}$ Another way to interpret trading is that it allows the government to tax capital excess returns: As is well known, this form of non-linear capital taxation is non-distorsionary.

${ }^{3}$ This is also potentially useful to compute the value of non-traded government liabilities, as for example dispensing with future nuclear waste, honoring implicit social contracts etc.
} 
I prove that in my model, an analogous result holds for the intertemporal term. Moreover, as Zhu (1992) and Chari, Christiano and Kehoe (1994) pointed out, if preferences are homogenous and separable between consumption and leisure, a stronger version of the zero capital tax result applies: Taxes on capital should be zero from the second period on. Echoing this result, I show that if preferences are quasi-linear, the intertemporal term is zero. However outside of this case, homogenous preferences do not imply that the intertemporal term should be zero in my model.

The paper also contributes to the literature on fiscal policy in incomplete markets pioneered by Barro (1979). Barro considered a deterministic, partial equilibrium environment and associated an exogenous convex deadweight cost to taxes. Variations in the deadweight costs are costly; a benevolent government should therefore seek to smooth taxes across time. Barro showed that just like consumption smoothing problems, tax smoothing by the government imparts a random walk component to taxes and public debt. Most closely related to this paper is Aiyagari, Marcet, Sargent and Seppälä (2002) and, more recently, Werning (2005). They studied fiscal policy in general equilibrium under incomplete markets. They analyzed a version of the no capital economy in Lucas and Stokey (1983) with only risk free debt. They showed that Ramsey outcomes display features of Barro's model. In particular, labor taxes inherit a near unit root component. I extend this line of research by introducing capital along with a more general asset structure, and studying capital taxation in addition to labor taxation. I demonstrate that the results of Aiyagari, Marcet, Sargent and Seppälä (2002) carry through when capital is introduced: Labor taxes and government debt inherit a random walk component.

Finally, this paper is related to literature studying the optimal liability structure of the government under incomplete markets. The foundational paper is Bohn (1990). Bohn considered a stochastic version of Barro's model with risk neutral consumers and an ad hoc convex cost for distortionary taxes. The literature on the optimal portfolio of the government under incomplete markets has entirely focused Bohn's model, maintaining the assumption of risk neutrality and adopting an ad hoc deadweight cost for taxes. My model provides microfoundations for Bohn's findings, and shows that important caveats to his theory need to be introduced. I also analyze explicitly the situation where consumers are risk averse. This goes beyond existing contributions.

Angeletos (2002) and Buera and Nicolini (2004) assume that markets are incomplete: the government can only trade risk free debt with multiple maturities. They show that generically, the government can replicate the complete market allocation when enough maturities are traded, and characterize the optimal maturity structure of government debt in such instances.

The central idea in this paper that non-state contingent taxes have important risk sharing implications can be traced back to Stiglitz $(1969)^{4}$. Stiglitz considered the partial equilibrium problem of a consumer that must decide how to allocate a given amount of wealth between a riskless asset and a risky asset. He examined how the government can affect the allocation of wealth and welfare using a variety of linear taxes. My model can be seen as a general equilibrium risk sharing model between the government and the agents. As in Stiglitz (1969), linear taxes on assets - here capital - have

\footnotetext{
${ }^{4}$ I thank Abhijit Banerjee for pointing this analogy to me.
} 
hedging consequences. However, I show that taking into account the distortionary consequences of linear taxes by analyzing the savings margin - taken as inelastic in Stiglitz's analysis - is crucial.

On the methodological side, this paper builds on Werning (2005). Existing models either adopt a Lagrangian approach - as for example Aiyagari, Marcet, Sargent and Seppälä (2002) - or develop a recursive representation by incorporating some multipliers in the state space - an approach initiated by Marcet and Marimon (1998). Werning (2005) revisits Aiyagari, Marcet, Sargent and Seppälä’s model and develops a recursive representation with three state variables: debt, expected marginal utility one period ahead, and the state of the Markov shock process. I develop a parsimonious recursive representation of the Ramsey problem with only four state variables, which are directly related to the allocation: the present value of government liabilities, capital, past marginal utility and the state of the Markov shock process. In the particular case where preferences are quasilinear, I am able to reduce the state space to two state variables: the present value of government liabilities and the state of the Markov shock process. Developing a recursive approach using only variables directly linked to the allocation allows a better understanding of the properties of Ramsey outcomes, is useful for developing intuition, simplifies calculations, and in some cases, permits easier numerical simulations.

The rest of the paper is organized as follows. Section 2 introduces the economic environment, sets up the Ramsey problem, and develops a recursive representation. Section 3 presents the properties of debt and taxes in the quasi-linear preferences case. I analyze the general case in Section 4. In Section 5, I study capital ownership by the government and characterize the optimal liability structure of the government. All proofs omitted in the main text are contained in the Appendix.

\section{The Economy}

The model is a neoclassical, stochastic production economy. The economy is populated by a continuum of identical, infinite-lived individuals and a government.

Time is discrete, indexed by $t \in\{0,1, \ldots\}$. The exogenous stochastic disturbances in period $t$ are summarized by a discrete random variable $s_{t} \in \mathbb{S} \equiv\{1,2, \ldots, S\}:$ the state at date $t$. I let $s^{t} \equiv\left\{s_{0}, s_{1}, \ldots, s_{t}\right\} \in \mathbb{S}^{t}$ denote the history of events at date $t$. I assume that $s_{t}$ follows a Markov process with transition density $P\left(s^{\prime} \mid s\right)$ and initial distribution $\pi_{0}=P\left(. \mid s_{-1}\right)$.

In each period $t$, the economy has two goods: a consumption-capital good and labor. Households have access to an identical constant returns to scale technology to transform capital $k_{t-1}$ and labor $l_{t}$ into output via the production function $k_{t-1}+F\left(k_{t-1}, l_{t}, s_{t}\right)^{5}$. The production function is smooth in $\left(k_{t-1}, l_{t}\right)$ and satisfies the standard Inada conditions. Notice that this formulation incorporates a stochastic productivity shock. The output can be used for private consumption $c_{t}$, government consumption $g_{t}$, and new capital $k_{t}$. Throughout, I will take government consumption $g_{t}=g\left(s_{t}\right)$ to be exogenously specified. Therefore, the resource constraints in the economy are

\footnotetext{
${ }^{5}$ This formulation allows for capital depreciation. The depreciation of capital is subsumed in the production function $F\left(k_{t-1}, l_{t}, s_{t}\right)$.
} 


$$
c_{t}+g_{t}+k_{t} \leq F\left(k_{t-1}, l_{t}, s_{t}\right)+k_{t-1}, \quad \forall t \geq 0 \text { and } s^{t} \in \mathbb{S}^{t}
$$

Households rank consumption streams according to

$$
\mathbb{E}_{-1} \sum_{t=0}^{\infty} \beta^{t} u\left(c_{t}, l_{t}, s_{t}\right)
$$

where $\beta \in(0,1)$ and $u$ is smooth and concave in $\left(c_{t}, l_{t}\right)$, increasing in consumption, decreasing in labor, and satisfies the standard Inada conditions. Note that this formulation incorporates a stochastic preference shock.

The government raises all revenues through a tax on labor income $\tau_{t}^{l}$ and a tax on capital income $\tau_{t}^{k}$. Except for taxes on capital $\tau_{t}^{k}$, households and the government make decisions whose time $t$ components are functions of the history of shocks $s^{t}$ up up to $t$. By contrast, I assume that taxes on capital are predetermined: the government makes decisions on $\tau_{t}^{k}$ one period in advance. Hence $\tau_{t}^{k}$ is a function of the history of shocks up to $t-1, s^{t-1}$. The capital stock $k_{0}$ is inelastic, hence providing a non distortionary source of revenues to the government. In order to limit the amount of revenues the government can extract at no cost, I assume that the date 0 tax rate on capital $\tau_{0}^{k}$ is exogenously fixed.

The assumption that taxes on capital are set one period in advance deserves some discussion. It is more efficient to postpone this discussion below after some definitions have been introduced.

Incomplete markets and debt limits. Households and the government borrow and lend only in the form of risk-free one period bonds paying interest $r_{t}\left(s^{t-1}\right)$ in every state at date $t$. The government budget and debt limit constraints are $^{6}$ :

$$
\begin{gathered}
\left(1+r_{t}\right) b_{t-1}^{g} \leq \tau_{t}^{l} l_{t} w_{t}+\tau_{t}^{k}\left(F\left(k_{t-1}, l_{t}, s_{t}\right)-w_{t} l_{t}\right)+b_{t}^{g}, \quad \forall t \geq 0 \text { and } s^{t} \in \mathbb{S}^{t} \\
\underline{M}\left(k_{t}, u_{c}\left(c_{t}, l_{t}, s_{t}\right), s_{t}\right) \leq u_{c}\left(c_{t}, l_{t}, s_{t}\right) b_{t}^{g} \leq \bar{M}\left(k_{t}, u_{c}\left(c_{t}, l_{t}, s_{t}\right), s_{t}\right), \quad t \geq 0 \text { and } s^{t} \in \mathbb{S}^{t}
\end{gathered}
$$

Here $b_{t}^{g}$ is the amount of government debt outstanding at date $t$. When (3) holds with strict inequality, I let the difference between the right hand side and the left hand side be a nonnegative level of lump sum transfers $T_{t}$ to the households. The upper and lower debt limits $\underline{M}\left(k_{t}, u_{c}\left(c_{t}, l_{t}, s_{t}\right), s_{t}\right)$, $\bar{M}\left(k_{t}, u_{c}\left(c_{t}, l_{t}, s_{t}\right), s_{t}\right)$ in (4) influence the optimal government plan. In full generality, I allow the debt limits to depend on the capital stock of the economy and the current marginal utility of consumption. I discuss alternative possible settings for $\underline{M}\left(k_{t}, u_{c}\left(c_{t}, l_{t}, s_{t}\right), s_{t}\right), \bar{M}\left(k_{t}, u_{c}\left(c_{t}, l_{t}, s_{t}\right), s_{t}\right)$ below. Note that I define debt and asset limits on $u_{c}\left(c_{t}, l_{t}, s_{t}\right) b_{t}^{g}$ instead of $b_{t}^{g}$. This is natural given my definition of debt: $b_{t}^{g}$ is the amount of debt issued at the end of period $t$. The quantity $u_{c}\left(c_{t}, l_{t}, s_{t}\right) b_{t}^{g}$ is therefore just debt weighted by the state price density.

The representative household operates a firm and supplies and hires labor at wage $w_{t}$ on a

\footnotetext{
${ }^{6}$ Note that in a specification with capital depreciation, this formulation supposes that capital depreciation is deductible.
} 
competitive market. ${ }^{7}$ The household's problem is to choose stochastic processes $\left\{c_{t}, l_{t}, l_{t}^{d}, k_{t}\right\}$ to maximize (2) subject to the sequence of budget constraints

$$
c_{t}+b_{t}^{g} \leq\left(1-\tau_{t}^{l}\right) w_{t} l_{t}+\left(1-\tau_{t}^{k}\right)\left(F\left(k_{t-1}, l_{t}^{d}, s_{t}\right)-w_{t} l_{t}^{d}\right)+k_{t-1}-k_{t}+\left(1+r_{t}\right) b_{t-1}^{g}+T_{t}
$$

taking wages, interest rates and taxes $\left\{w_{t}, r_{t}, \tau_{t}^{l}, \tau_{t}^{k}\right\}_{t \geq 0}$ as given. Here $b_{t}^{g}$ represents the household's holding of government debt, $l_{t}^{d}$ the household's labor demand and $l_{t}$ the household's labor supply. The stochastic processes $\left\{c_{t}, l_{t}, l_{t}^{d}, k_{t}\right\}_{t \geq 0}$ must be measurable with respect to $s^{t}$. The labor market clears if $l_{t}=l_{t}^{d}$.

The household also faces debt limits analogous to (4), which I assume are less stringent than those faced by the government. Therefore, in equilibrium, the household's problem always has an interior solution. The household's first order conditions require that two Euler equations hold, one for the risk free rate and the other for the net return on capital, in addition to a labor-leisure arbitrage condition and the condition that labor is paid its marginal product.

$$
\begin{aligned}
1 & =\left(1+r_{t}\right) \mathbb{E}_{t}\left\{\beta \frac{u_{c, t+1}}{u_{c, t}}\right\}, \quad \forall t \geq 0 \text { and } s^{t} \in \mathbb{S}^{t} \\
1 & =\mathbb{E}_{t}\left\{\beta \frac{u_{c, t+1}}{u_{c, t}}\left[1+\left(1-\tau_{t}^{k}\right) F_{k, t+1}\right]\right\}, \quad \forall t \geq 0 \text { and } s^{t} \in \mathbb{S}^{t} \\
\tau_{t}^{l} & =1+\frac{u_{l, t}}{u_{c, t w_{t}}}, \quad \forall t \geq 0 \text { and } s^{t} \in \mathbb{S}^{t} \quad \quad \forall t \geq 0 \text { and } s^{t} \in \mathbb{S}^{t} \\
w_{t} & =F_{l}\left(k_{t-1}, l_{t}^{d}, s_{t}\right), \quad
\end{aligned}
$$

Remark 1 Note for future reference that $w_{t}=F_{l}\left(k_{t-1}, l_{t}^{d}, s_{t}\right)$ implies, using the constant return to scale assumption, that $F\left(k_{t-1}, l_{t}^{d}, s_{t}\right)-w_{t} l_{t}^{d}=k_{t-1} F_{k}\left(k_{t-1}, l_{t}^{d}, s_{t}\right)$. Hence if this condition holds, revenues from capital taxation can be written as $\tau_{t}^{k} k_{t-1} F_{k}\left(k_{t-1}, l_{t}^{d}, s_{t}\right)$.

Definition 1 Given $b_{-1}^{g}, r_{0}, k_{0}, \tau_{0}^{k}$ and a stochastic process $\left\{s_{t}\right\}_{t \geq 0}$, a feasible allocation is a stochastic process $\left\{c_{t}, l_{t}, k_{t}\right\}_{t \geq 0}$ satisfying (1) whose time $t$ elements are measurable with respect to $s^{t}$.A risk free rate process $\left\{r_{t}\right\}_{t \geq 0}$, a wage process $\left\{r_{t}\right\}_{t_{\geq 0}}$ and a government policy $\left\{\tau_{t}^{l}, \tau_{t}^{k}, b_{t}^{g}\right\}_{t \geq 0}$ is a set of stochastic processes such that $w_{t}, \tau_{t}^{l}$ and $b_{t}^{g}$ are measurable with respect to $s^{t}, \tau_{t}^{k}$ and $r_{t}$ are measurable with respect to $s^{t-1}$.

Definition 2 Given $b_{-1}^{g}, r_{0}, k_{0}, \tau_{0}^{k}$ and a stochastic process $\left\{s_{t}\right\}$, a competitive equilibrium is a feasible allocation, a risk free rate process, a wage process and a government policy such that $\left\{c_{t}, l_{t}, l_{t}, k_{t}\right\}_{t \geq 0}$ solves the household's optimization problem, and the government budget constraints (3) and (4) are satisfied. ${ }^{8}$

\footnotetext{
${ }^{7}$ Giving the firms to consumers is just one of the many equivalent ways of resolving the indeterminacy of the the objective of competitive firms under incomplete markets.

${ }^{8}$ Note that this definition imposes that the labor market clears by imposing that the third argument in $\left\{c_{t}, l_{t}, l_{t}, k_{t}\right\}$ is equal to the second.
} 
Definition 3 The Ramsey problem is to maximize (2) over competitive equilibria. A Ramsey outcome is a competitive equilibrium that attains the maximum.

Discussion of debt limits. By analogy with Aiyagari, Marcet, Sargent and Seppälä (2002), henceforth AMSS, I shall study two kinds of debt limits, called natural and ad hoc. Natural debt limits amount to imposing that debt be less than the maximum debt that could be repaid almost surely under an optimal tax policy. Following AMSS, I call a debt or asset limit ad hoc if it is more stringent than the natural one. In this model, natural debt limits, which depend on the capital stock $k_{t}$ in the economy, are in general difficult to compute. But as mentioned above, it is easy to see that they are of the form $\underline{M}^{n}\left(k_{t}, u_{c}\left(c_{t}, l_{t}, s_{t}\right), s_{t}\right) \leq u_{c}\left(c_{t}, l_{t}, s_{t}\right) b_{t}^{g} \leq \bar{M}^{n}\left(k_{t}, u_{c}\left(c_{t}, l_{t}, s_{t}\right), s_{t}\right)$. Imposing that debt limits are weakly tighter than the natural ones rules out Ponzi schemes.

Discussion of the measurability assumption for $\tau_{t}^{k}$. It is well known since the work of Judd (1992) and Chari, Christiano and Kehoe (1994) that with complete markets, taxes on capital are indeterminate: the government faces an embarrassment of riches, with too many instruments to implement the Ramsey outcome. In fact, the complete markets optimum can be implemented with complete markets and taxes on capital set one period in advance, or under incomplete markets with only a risk free bond but fully adjustable taxes on capital. The reason for this is that investment depends only on the average tax rate on capital, and not on the particular way it is spread between states. When only a risk free bond is traded, the government can take advantage of this and adjust taxes on capital to hedge its burden across states - thereby replicating the complete markets outcome.

Inertia in fiscal policy - captured here by the assumption that taxes have to be set one period in advance - restricts the state-contingency of capital taxes, prevents replication of the complete markets allocation, and requires analyzing optimal taxes on capital in a truly incomplete markets environment.

Because they are not the focus of this paper, taxes on labor, on the other hand, are left fully adjustable. One may wonder whether this asymmetric treatment of labor and capital taxes doesn't bias the results in favor of labor taxation. But in fact, most of the insights that I derive would still be valid if additional restrictions were put on labor taxes. Of course, the exact results depend on the particular form of these restrictions. But for example, if the production function is Cobb Douglas - with or without depreciation - the formulas for taxes on capital (22) and (28) are still valid if taxes on labor are also restricted to be set one period in advance. The reason is that in this case, capital can be factored out from the additional restrictions imposed on the planing problem.

\section{A Recursive Representation for the Ramsey Problem}

The following lemma characterizes the restrictions that the government budget and behavior of households place on competitive equilibrium feasible allocations, risk free rate processes and government policies. 
Lemma 1 A feasible allocation $\left\{c_{t}, l_{t}, k_{t}\right\}_{t \geq 0}$, a risk free rate process $\left\{r_{t}\right\}_{t \geq 0}$, a wage process $\left\{w_{t}\right\}_{t \geq 0}$, and a government policy $\left\{\tau_{t}^{l}, \tau_{t}^{k}, b_{t}^{g}\right\}_{t \geq 0}$ constitute a competitive equilibrium if and only if (1), (3), hold with equality and (4), (6), (7), (8) and (9), hold, with $l_{t}=l_{t}^{d}$.

I develop a recursive representation of the Ramsey problem from $t=1$ on. This recursive representation uses four state variables: The value of the capital stock $k$ inherited from the previous period, the value of government debt from the previous period $b$, the marginal utility of consumption in the previous period $\theta \equiv u_{c}\left(c_{-}, l_{-}, s_{-}\right)$and the shock that hit the economy in the previous period $s_{-}$. It is easy to see that the planning problem is recursive in these four state variables, and that the value function of the government satisfies the following Bellman equation.

\section{Bellman equation 1}

$$
V\left(k, b, \theta, s_{-}\right)=\max \mathbb{E}\left\{u\left(c_{s}, l_{s}, s\right)+\beta V\left(k_{s}^{\prime}, b_{s}^{\prime}, u_{c}\left(c_{s}, l_{s}, s\right), s\right) \mid s_{-}\right\}
$$

subject to

$$
\begin{gathered}
(1+r) \mathbb{E}\left\{\beta u_{c}\left(c_{s}, l_{s}, s\right) \mid s_{-}\right\}=\theta \\
\mathbb{E}\left\{\beta u_{c}\left(c_{s}, l_{s}, s\right)\left[1+\left(1-\tau^{k}\right) F_{k}\left(k, l_{s}, s\right)\right] \mid s_{-}\right\}=\theta \\
\tau_{s}^{l}=1+\frac{u_{l}\left(c_{s}, l_{s}, s\right)}{u_{c}\left(c_{s}, l_{s}, s\right) F_{l}\left(k, l_{s}, s\right)}, \quad \forall s \in \mathbb{S} \\
(1+r) b+g_{s} \leq \tau_{s}^{l} l_{s} F_{l}\left(k, l_{s}, s\right)+\tau^{k} k F_{k}\left(k, l_{s}, s\right)+b_{s}^{\prime}, \quad \forall s \in \mathbb{S} \\
c_{s}+g_{s}+k_{s}^{\prime} \leq F\left(k, l_{s}, s\right)+k, \quad \forall s \in \mathbb{S} \quad \\
\underline{M}\left(k_{s}^{\prime}, u_{c}\left(c_{s}, l_{s}, s\right), s\right) \leq u_{c}\left(c_{s}, l_{s}, s\right) b_{s}^{\prime} \leq \bar{M}\left(k_{s}^{\prime}, u_{c}\left(c_{s}, l_{s}, s\right), s\right), \quad \forall s \in \mathbb{S}
\end{gathered}
$$

The constraints on the problem are, in order of appearance: (i) that the risk free rate satisfies the usual Euler equation; (ii) that the net return on capital satisfies the usual Euler equation; (iii) that agents equalize their marginal rates of substitutions between leisure and consumption to the net real wage; (iv) that the budget constraint of the government is satisfied in each state $s \in \mathbb{S}$; (v) that the resource constraint holds in each state $s \in \mathbb{S}$ and (vi) that the amount of government debt issued in each state $s \in \mathbb{S}$ satisfies the debt and asset limits.

The initial period must be treated in isolation since there, marginal utility of consumption in the previous period is not defined. Equivalently, one can think of the problem at date $t=0$ as solving $V\left(k_{0}, b_{-1}^{g}, \theta_{0}, s_{-1}\right)$ with the additional constraint that the date 0 tax on capital is given by $\tau_{0}^{k}$ and that $\theta_{0}$ is such that the implied date 0 risk free rate is equal to $r_{0}$. Hence it is straightforward to obtain the entire solution for the Ramsey problem once the solution to the Bellman equation above has been found.

It will prove convenient to replace $b$ by a new state variable $\tilde{b}=b \theta$ representing debt weighted by the state price density. I can then define the corresponding value function $\tilde{V}\left(k, \tilde{b}, \theta, s_{-}\right)=$ $V\left(k, b \theta, \theta, s_{-}\right)$. In order to write the Bellman equation satisfied by $\tilde{V}$, I first rearrange the constraints. I use the first constraint to substitute $r$, the third to substitute $\tau_{s}^{l}$, and I multiply the fourth 
constraint by $u_{c}\left(c_{s}, l_{s}, s\right)$. To save on notation I write $X_{s}$ for any function $X\left(k, k_{s}^{\prime}, \tilde{b}_{s}^{\prime}, l_{s}, s\right)$ in state $s$.

\section{Bellman equation 2}

$$
\tilde{V}\left(k, \tilde{b}, \theta, s_{-}\right)=\max \mathbb{E}\left\{u_{s}+\beta \tilde{V}\left(k_{s}^{\prime}, \tilde{b}_{s}^{\prime}, u_{c, s}, s\right) \mid s_{-}\right\}
$$

subject to

$$
\begin{gathered}
\mathbb{E}\left\{\beta u_{c, s}\left[1+\left(1-\tau^{k}\right) F_{k, s}\right] \mid s_{-}\right\}=\theta \\
\tilde{b} \frac{u_{c, s}}{\beta \mathbb{E}\left\{u_{c, s} \mid s_{-}\right\}}+g_{s} u_{c, s} \leq l_{s} F_{l, s} u_{c, s}+l_{s} u_{l, s}+\tau^{k} k F_{k, s} u_{c, s}+\tilde{b}_{s}^{\prime}, \quad \forall s \in \mathbb{S} \\
c_{s}+g_{s}+k_{s}^{\prime} \leq F_{s}+k, \quad \forall s \in \mathbb{S} \\
\underline{M}\left(k_{s}^{\prime}, u_{c, s}, s\right) \leq \tilde{b}_{s}^{\prime} \leq \bar{M}\left(k_{s}^{\prime}, u_{c, s}, s\right), \quad \forall s \in \mathbb{S}
\end{gathered}
$$

The presence of capital, capital taxes, and marginal utility make the constraint set in (10) nonconvex. This poses two kinds of problems. First, first order conditions are necessary but not sufficient for characterizing the solution. Second, it considerably complicates the task of establishing the differentiability of the value function $\tilde{V}$ - which is required to partially characterize the solution by a set of necessary first order conditions.

All the properties of Ramsey outcomes I derive can be established using either a Lagrangian approach, or expanding the Bellman equation (10) over two periods - hence bypassing this technical difficulty, but at the cost of heavier notations and poorer intuition. I therefore proceed assuming the value function $\tilde{V}$ is differentiable in $(k, \tilde{b}, \theta)$, and refer the reader to the appendix for an approach that does not rely on this assumption.

\section{The Quasi-Linear Case}

In the Ramsey problem, the government simultaneously chooses taxes and manipulates intertemporal prices. Manipulating prices substantially complicates the problem, especially with incomplete markets. Here I simplify by adopting a specification of preferences that eliminates the government's ability to manipulate prices. As in AMSS, this brings the model into the form of a consumption smoothing model and allows me to adapt results for that model to the Ramsey problem.

I assume that $u(c, l, s)=c+H(l, s)$, where $H$ is a smooth, decreasing and concave function. I assume $H^{\prime}(0)=\infty$ in order for labor supply to be interior. Making preferences linear pins down intertemporal prices. This allows a drastic simplification of (10), as two state variables $b$ - which is equal to $\tilde{b}$ in this case - and $s_{-}$are now sufficient to describe the state of the economy. Intuitively, the reasons for this simplification are twofold. The first reason is that $\theta$ is now fixed and equal to 1

- hence $\theta$ can be dropped as a state variable. The other reason is that, intertemporal prices being entirely pinned down, I can perform a change of timing in the recursive approach: The optimal investment in capital $k$ can now be thought as being chosen simultaneously with the the tax rate 
on capital $\tau^{k}$ - which allows to turn the state variable $k$ into a control variable.

Under this specification, natural debt limits are independent of the capital stock, and marginal utility is constant: $\underline{M}^{n}\left(k, u_{c}, s\right)=\underline{M}_{s}^{n}$ and $\bar{M}^{n}\left(k, u_{c}, s\right)=\bar{M}_{s}^{n}$. Consistent with this property, in this setup, I consider only fixed debt limits $\underline{M}_{s}$ and $\bar{M}_{s}$. After further simplifying the constraints by using the resource constraint to substitute $c_{s}$, I derive a new Bellman equation.

\section{Bellman equation 3}

$$
\tilde{V}\left(\tilde{b}, s_{-}\right)=\max \mathbb{E}\left\{F_{s}+k\left(1-\frac{1}{\beta}\right)-g_{s}+\beta \tilde{V}\left(\tilde{b}_{s}^{\prime}, s\right) \mid s_{-}\right\}
$$

subject to

$$
\begin{gathered}
\mathbb{E}\left\{\beta\left[1+\left(1-\tau^{k}\right) F_{k, s}\right] \mid s_{-}\right\}=1 \\
\tilde{b} \frac{1}{\beta}+g_{s} \leq l_{s} F_{l, s}+l_{s} H_{l, s}+\tau^{k} k F_{k, s}+\tilde{b}_{s}^{\prime}, \quad \forall s \in \mathbb{S} \\
\underline{M}_{s} \leq \tilde{b}_{s}^{\prime} \leq \bar{M}_{s}, \quad \forall s \in \mathbb{S}
\end{gathered}
$$

\subsection{Stochastic properties of Ramsey outcomes}

I attach a multiplier $\mu$ to (16), $\nu_{s}$ to (17) and $\nu_{2, s}$ and $\nu_{1, s}$ to the two constraints in (18). I can then form a Lagrangian associated with the right hand side of (15)

$$
\begin{aligned}
L\left(\tilde{b}, s_{-}\right)= & \mathbb{E}\left\{F_{s}+k\left(1-\frac{1}{\beta}\right)-g_{s}+\beta \tilde{V}\left(\tilde{b}_{s}^{\prime}, s\right)+\mu\left[1-\beta\left[1+\left(1-\tau^{k}\right) F_{k, s}\right]\right] \mid s_{-}\right\} \\
& +\mathbb{E}\left\{\nu_{s}\left[l_{s} F_{l, s}+l_{s} H_{l, s}+\tau^{k} k F_{k, s}+\tilde{b}_{s}^{\prime}-\tilde{b} \frac{1}{\beta}-g_{s}\right]+\nu_{2, s}\left[\tilde{b}_{s}^{\prime}-\underline{M}\right]+\nu_{1, s}\left[\bar{M}-\tilde{b}_{s}^{\prime}\right] \mid s_{-}\right\}
\end{aligned}
$$

where $\mu, \nu_{s}, \nu_{1, s}$ and $\nu_{2, s}$ are functions of $\tilde{b}$ and $s_{-}$.

The Envelope condition delivers

$$
\beta \tilde{V}_{b}\left(\tilde{b}, s_{-}\right)=-\mathbb{E}\left\{\nu_{s} \mid s_{-}\right\}
$$

and the first order condition for $\tilde{b}_{s}^{\prime}$ gives

$$
\beta \tilde{V}_{b}\left(\tilde{b}_{s}^{\prime}, s\right)=-\nu_{s}+\nu_{1, s}-\nu_{2, s}
$$

Combining these two equations, I find that, denoting by $\nu_{s_{-}}, \nu_{1, s_{-}}$and $\nu_{2, s_{-}}$the corresponding multipliers in the previous period, the following martingale equation hold

$$
\nu_{s-}=\mathbb{E}\left\{\nu_{s} \mid s_{-}\right\}+\nu_{1, s_{-}}-\nu_{2, s_{-}}
$$

In the rest of the this section, I will often, with some abuse of notation, switch from recursive notations to sequential notations.

Therefore, off debt-limits, $\nu_{s_{-}}=\mathbb{E}\left\{\nu_{s} \mid s_{-}\right\}$. Using sequential notations, the process $\left\{\nu_{t}\right\}$ is a 
positive martingale. Equation (20) then shows that debt $\tilde{b}_{t}$ is a non-linear invariant function of $-\nu_{t}+\nu_{1, t}-\nu_{2, t}$ and $s_{t}$, and hence inherits a near random walk component. The policy functions $\left\{l_{s}, k, \tau^{k}\right\}$ associated with (15) show that for a Ramsey outcome, $c_{t}, l_{t}$ and $\tau_{t}^{l}$ are invariant functions of $\tilde{b}_{t-1}, s_{t-1}$ and $s_{t}$, while $k_{t-1}$ and $\tau_{t}^{k}$ are invariant functions of $\tilde{b}_{t-1}$ and $s_{t-1}$.

Debt and taxes - on both labor and capital - therefore inherit a random walk component, reflecting the desire to smooth distortionary taxes across states and time. This tax smoothing intuition is familiar in incomplete markets environments since the work of Barro (1979) and AMSS. Note that under complete markets, a similar Bellman equation would hold, but $\nu_{t}$ would be constant across time and states, and not a mere martingale. Therefore debt and taxes would depend only on the current shock $s_{t}$ affecting the economy as well as on $s_{t-1}$, and would hence inherit the serial correlation properties of $\left\{s_{t}\right\}$, as in Lucas and Stokey (1983).

The fact that capital taxes, when set optimally, have a random walk component - and hence are persistent - is new, and might come as a surprise when confronted with the results of Chamley (1986) and Judd (1985). This reflects the fact that hedging needs of the government depend on the level of government debt, which has a random walk component. When public debt is low, the government is free to raise debt when confronted with an adverse shock : debt is then a good shock absorber. By contrast, when public debt is close to the debt limit, the ability of the government to shift the tax burden to the future is restricted. Hedging through capital taxes is then more attractive. As the simulations below will show, $\tau_{t}^{k}$ is an extremely non-linear function of $\tilde{b}_{t-1}-$ in all simulations increasing and convex. This reflects the non-linearity in government hedging needs, and is a contrast with labor taxes.

\subsection{Taxes on capital}

Manipulating the first order conditions, it is possible to derive a formula to characterize taxes on capital

$$
\tau^{k}=\frac{\frac{\mathbb{E}\left\{-\left(1-\tau^{k}\right) k F_{k k, s} \mid s_{-}\right\}}{\mathbb{E}\left\{F_{k, s} \mid s_{-}\right\}}}{1+\frac{\mathbb{E}\left\{F_{k, s} \nu_{s} \mid s_{-}\right\}}{\mathbb{E}\left\{F_{k, s} \mid s_{-}\right\}}}\left[\frac{\operatorname{Cov}\left\{k F_{k, s}, \nu_{s} \mid s_{-}\right\}}{\mathbb{E}\left\{k F_{k, s} \mid s_{-}\right\}}-\frac{\operatorname{Cov}\left\{k F_{k k, s}, \nu_{s} \mid s_{-}\right\}}{\mathbb{E}\left\{k F_{k k, s} \mid s_{-}\right\}}\right]
$$

The left hand side of (22) is increasing in $\tau^{k}$. The right hand side comprises three terms. The first term

$$
\frac{\frac{\mathbb{E}\left\{-\left(1-\tau^{k}\right) k F_{k k, s} \mid s_{-}\right\}}{\mathbb{E}\left\{F_{k, s} \mid s_{-}\right\}}}{1+\frac{\mathbb{E}\left\{F_{k, s} \nu_{s} \mid s_{-}\right\}}{\mathbb{E}\left\{F_{k, s} \mid s_{-}\right\}}}
$$

has as its numerator the inverse of the elasticity of capital $k$ to taxes on capital $\tau^{k}$. This inverse elasticity factor is standard in the taxation literature. The higher the elasticity, the lower the absolute value of the tax rate.

The second term

$$
\frac{\operatorname{Cov}\left\{k F_{k, s}, \nu_{s} \mid s_{-}\right\}}{\mathbb{E}\left\{k F_{k, s} \mid s_{-}\right\}}
$$


represents the direct effect of an increase in $\tau^{k}$ : it relaxes the budget constraint of the government (17) in state $s$ in proportion to the tax base of $\tau^{k}, k F_{k, s}$. The more $k F_{k, s}$ is correlated with $\nu_{s}$, the higher the optimal $\tau^{k}$, as taxes on capital pay better in states where the budget constraint of the government is more binding, i.e. where the need for funds is higher.

The third term

$$
-\frac{\operatorname{Cov}\left\{k F_{k k, s}, \nu_{s} \mid s_{-}\right\}}{\mathbb{E}\left\{k F_{k k, s} \mid s_{-}\right\}}
$$

reflects the indirect effect of an increase in $\tau^{k}$. Increasing $\tau^{k}$ affects investment $k$ and hence the capital tax base $k F_{k, s}$ and the revenues from labor taxation $l_{s} F_{l, s}+l_{s} H_{l, s}$ in each state $s \in \mathbb{S}$. The formula makes use of the constant returns to scale assumption to replace $l_{s} F_{k l, s}$ by $-k F_{k k, s}$. How adverse these effects are depends on the correlation between $k F_{k k, s}$ and $\nu_{s}$. The higher the correlation, the bigger the effects in states where the need for funds is high, and hence the lower $\tau^{k}$.

Hence, (22) brings together a standard inverse elasticity factor with two terms that have an asset pricing feel, and reflect the government's desire to use taxes on capital set one period in advance to hedge its need for funds across states. This illustrates that the government uses capital taxes not to levy funds on average, but only to smooth its need for funds across states - a stark difference with labor taxes.

In a complete market environment, (22) still holds, but $\nu_{s}$ is constant across states, so that $\tau^{k}$ is equal to 0 . This outcome is then a particular case of the classical uniform taxation result by Atkinson and Stilgitz (1972), transposed to this Ramsey setup by Zhu (1992) and Chari, Christiano and Kehoe (1994), which holds more generally for preferences which are CRRA and separable between consumption and leisure.

As the following proposition shows, this zero tax result carries through in a particular case.

Proposition 1 If $F$ is Cobb Douglas, $\tau_{t}^{k}=0$ for all $t \geq 1$.

Therefore, for the strong Cobb Douglas benchmark, taxes on capital are 0 from period 1 on. In this case where the elasticity of substitution between capital and labor $\sigma$ is equal to 1, the hedging benefits from the direct effect of a marginal increase in $\tau^{k}$ at $\tau^{k}=0$ are exactly offset by the marginal hedging cost from the indirect effect through the capital tax base and labor revenues.

Remark 2 Equation (22) and Proposition 1 are valid irrespective of the asset structure of the economy. It holds for example if the government is required to balance its budget in every period, if it is restricted to trade only a perpetuity etc.

In the general non Cobb Douglas case, the sign of $\tau^{k}$ is ambiguous - it may be optimal to tax or subsidize capital. The sign of $\tau^{k}$ will in general depend on the way productivity shocks and preference shocks interact with government consumption shocks and on the particular functional form for the production function. Under technical conditions, It is possible to characterize the sign of $\tau^{k}$ in special cases. 
Proposition 2 1) Assume that $F$ is CES with elasticity of substitution $\sigma$. Consider the case where productivity shocks are Hicks neutral. The following holds: (i) if $\sigma>1$, and if $l_{s}>l_{s^{\prime}}$ if and only if $\nu_{s}<\nu_{s^{\prime}}$, then $\tau^{k}>0$; (ii) if $\sigma>1$, and if $l_{s}<l_{s^{\prime}}$ if and only if $\nu_{s}<\nu_{s^{\prime}}$, then $\tau^{k}<0$; (iii) if $\sigma<1$, and if $l_{s}>l_{s^{\prime}}$ if and only if $\nu_{s}<\nu_{s^{\prime}}$, then $\tau^{k}<0$; (iv) if $\sigma<1$, and if $l_{s}<l_{s^{\prime}}$ if and only if $\nu_{s}<\nu_{s^{\prime}}$, then $\tau^{k}>0$. 2) Assume that $F(k, l)=A(s) k^{\alpha} l^{1-a}-\delta k$ : then $\tau^{k}$ has the same sign as $\operatorname{Cov}\left\{F_{k, s}, \nu_{s} \mid s_{-}\right\}$.

This proposition is partly unsatisfactory as it relies on an assumption on endogenous objects $l_{s}$ and $\nu_{s}$. It is natural, for example, to expect case (i) in the absence of productivity or preference shocks: it is reasonable to expect that in this environment with no wealth effects, a higher need for funds calls for higher taxes on labor resulting in lower labor supply. Non-convexities in (15) considerably complicate the task of establishing how $l_{s}$ co-varies with $\nu_{s}{ }^{9}$

Remark 3 Note that taxes on capital are zero when $\sigma=1$ and when $\sigma=\infty$ : absent productivity shocks, the marginal product of capital is fixed if capital and labor are perfect substitutes, and hence capital taxation provides no hedging benefits.

\subsection{Long run behavior}

The long run behavior of Ramsey outcomes is similar to AMSS. I refer the reader to this paper for an extensive discussion, and sketch the principal properties. Here the difference between natural and ad hoc debt limits is marked.

Under natural asset limits, the multiplier $\nu_{2, t}$ is zero throughout. The natural asset limit $-\underline{M}_{s}^{n}$ is the amount of assets that allows the government to withstand any sequence of shocks with zero taxes. It makes no sense for the government to accumulate more assets than $-\underline{M}_{s}^{n}$. When favorable shocks cause government assets to grow beyond $-\underline{M}_{s}^{n}$, it is optimal for the government to rebate consumers the difference via a lump sum rebate. Therefore (21) becomes

$$
\nu_{s_{-}}=\mathbb{E}\left\{\nu_{s} \mid s_{-}\right\}+\nu_{1, s_{-}}
$$

so that the stochastic process $\left\{\nu_{t}\right\}$ is a nonnegative supermartingale. Therefore, the supermartingale convergence theorem (see Lòeve (1977)) asserts that $\nu_{t}$ converges almost surely to a nonnegative random variable. As in AMSS, there are two possibilities:

(i) If the Markov process $\left\{s_{t}\right\}_{t \geq 0}$ is ergodic then the lemma below shows that under the condition that $\tilde{V}$ is concave in $\tilde{b}$ and that the policy functions in (15) are continuous, $\nu_{t}$ converges almost surely to zero. In that case, taxes $\tau_{t}^{k}$ and $\tau_{t}^{l}$ converge to the first best levels $\tau_{t}^{k}=0$ and $\tau_{t}^{l}=0$. In the limit, the level of government assets converges in state $s$ is $-\underline{M}_{s}^{n}$, the level of assets sufficient to finance the worst possible sequence of shocks forever from interest earnings.

\footnotetext{
${ }^{9}$ In the case where $F$ is CES with only government expenditure shocks or only technological shocks, for all the numerical simulations that I have performed, only cases (i) and (iii) ever occured. In the case where $F(k, l)=$ $A(s) k^{\alpha} l^{1-a}-\delta k$, with only technological shocks or only government expenditure shocks, for the numerical simulations that I have performed, $\operatorname{Cov}\left\{F_{k, s}, \nu_{s} \mid s_{-}\right\}$was always negative.
} 
(ii) If the Markov process $\left\{s_{t}\right\}_{t \geq 0}$ has an absorbing state, then $\nu_{t}$ can converge to a strictly positive value; $\nu_{t}$ converges when $s_{t}$ enters the absorbing state. From then on, taxes and all other variables in the model are constant. Taxes on capital are zero.

A technical assumption is necessary to rule out non-generic cases where the planner is able to achieve the complete markets allocation.

Assumption 1 For any $(b, s)$ such that $b>\underline{M}_{s}^{n}$, the complete markets allocation with initial condition $(b, s)$ is not a competitive equilibrium with incomplete markets.

Lemma 2 Consider the case of natural debt and asset limits. Assume that Assumption 1 holds, that the Markov process $\left\{s_{t}\right\}_{t \geq 0}$ is ergodic, that the value function $\tilde{V}$ is continuously differentiable and concave in $\tilde{b}$, and that the policy functions in (15) are continuous. Then $\nu_{t}$ converges to zero almost surely.

When the asset limit is more stringent than the natural one, convergence to the first best can be ruled out. In this case, the lower debt limit occasionally binds. This puts a nonnegative multiplier $\nu_{2, t}$ in $(21)$, and $\left\{\nu_{t}\right\}$ ceases to be a supermartingale. This fundamentally alters the limiting behavior of the model in the case where the Markov process $\left\{s_{t}\right\}_{t \geq 0}$ has a unique invariant distribution. In particular, rather than converging almost surely, $\nu_{t}$ continues to fluctuate randomly. Off debt limits, $\nu_{t}$ behaves like a martingale, and capital taxes do not converge to 0 .

In addition, if the range of the policy functions $\tilde{b}_{s}^{\prime}$ can be restricted to a compact set, one can show that an invariant distribution for government debt exists.

\section{The general case}

The insights from the simple example examined in the previous section largely carry through to the case where preferences are not risk neutral and separable. But the possibility to manipulate intertemporal prices brings about the traditional motive for taxes on capital, which interacts with the motive uncovered in the previous section.

\subsection{Stochastic properties of Ramsey outcomes}

Let us attach a multiplier $\mu$ to (11), $\nu_{s}$ to (12), $\nu_{2, s}$ and $\nu_{1, s}$ to the two constraints in (14), and $\psi_{s}$ to (13). I can then form a Lagrangian associated with the right hand side of (10)

$$
\begin{aligned}
L\left(k, \tilde{b}, \theta, s_{-}\right)= & \mathbb{E}\left\{u_{s}+\beta \tilde{V}\left(k_{s}^{\prime}, \tilde{b}_{s}^{\prime}, u_{c, s}, s\right)+\mu\left[\beta u_{c, s}\left[1+\left(1-\tau^{k}\right) F_{k, s}\right]-\theta\right] \mid s_{-}\right\} \\
& +\mathbb{E}\left\{\nu_{s}\left[-\tilde{b} \frac{u_{c, s}}{\beta \mathbb{E}\left\{u_{c, s}\right\}}-g_{s} u_{c, s}+l_{s} F_{l, s} u_{c, s}+l_{s} u_{l, s}+\tau^{k} k F_{k, s} u_{c, s}+\tilde{b}_{s}^{\prime}\right] \mid s_{-}\right\} \\
& +\mathbb{E}\left\{\psi_{s}\left[F_{s}+k-c_{s}-g_{s}-k_{s}^{\prime}\right]+\nu_{2, s}\left[\tilde{b}_{s}^{\prime}-\underline{M}\left(k_{s}^{\prime}, u_{c, s}, s\right)\right]+\nu_{1, s}\left[\bar{M}\left(k_{s}^{\prime}, u_{c, s}, s\right)-\tilde{b}_{s}^{\prime}\right] \mid s_{-}\right\}
\end{aligned}
$$

where $\mu, \nu_{s}, \nu_{1, s}, \nu_{2, s}$ and $\psi_{s}$ are functions of $k, \tilde{b}, \theta$ and $s_{-}$. 
Using the Envelope condition for $\tilde{b}$, a martingale equation similar to (21) can be derived

$$
\nu_{s-}=\frac{\mathbb{E}\left\{\nu_{s} u_{c, s} \mid s_{-}\right\}}{\mathbb{E}\left\{u_{c, s} \mid s_{-}\right\}}+\nu_{1, s_{-}}-\nu_{2, s_{-}}
$$

Off debt limits, the multiplier $\nu_{t}$ is a now a risk adjusted martingale, imparting, as in the simple example in the previous section, a unit root component to the solution of (10). The condition

$$
\left.\beta \tilde{V}_{b}\left(k_{s}^{\prime}, \tilde{b}_{s}^{\prime}, u_{c, s}, s\right)\right)=-\nu_{s}+\nu_{1, s}-\nu_{2, s}
$$

shows that the vector of endogenous state variables $\left\{k_{t-1}, \tilde{b}_{t}, u_{c, t-1}\right\}$ inherits a near random walk component. The policy functions $\left\{c_{s}, l_{s}, k, \tau^{k}\right\}$ associated with (10) imply that for a Ramsey outcome, $k_{t}, \tilde{b}_{t}, c_{t}, l_{t}$ and $\tau_{t}^{l}$ are invariant functions of $k_{t-1}, \tilde{b}_{t-1}, u_{c, t-1}, s_{t-1}$ and $s_{t}$, while $\tau_{t}^{k}$ is invariant function of $k_{t-1}, \tilde{b}_{t}, u_{c, t-1}$ and $s_{t-1}$. Therefore, $k_{t}, \tilde{b}_{t}, c_{t}, l_{t}, \tau_{t}^{l}$ and $\tau_{t}^{k}$ inherit a unit root component.

As in the risk neutral case, debt and taxes display a random walk component, reflecting the desire to smooth distortionary taxes across time, a sharp contrast with the complete markets Ramsey outcome, where a similar Bellman equation holds, but with $\nu_{t}$ constant across time and not a mere martingale.

Hence, the stochastic properties of Ramsey outcomes are similar to those discussed in the quasilinear example. The analysis is only made more difficult by the need to keep track of additional state variables $k_{t-1}$ and $u_{c, t-1}$.

\subsection{Taxes on capital}

A formula similar to (22) can be derived

$$
\tau^{k}=T^{h}\left(k, \tilde{b}, \theta, s_{-}\right)+T^{i}\left(k, \tilde{b}, \theta, s_{-}\right)+T^{b}\left(k, \tilde{b}, \theta, s_{-}\right)
$$

To save on space, I report the formulas for $T^{h}, T^{i}$ and $T^{b}$ in the first part of the Appendix. It should be noted that these are valid from $t=1$ on. There are three motives for taxing capital, corresponding to the three terms $T^{h}, T^{i}$ and $T^{b}$ on the right hand side of (28). ${ }^{10}$

The first term, $T^{h}$ is the "hedging" term and reflects the hedging motive discussed in the previous section. Two differences with (22) should be emphasized. First, the formula is adjusted for risk through $u_{c, s}$. Second, the multiplier $\psi_{s}$ on the resource constraint (13) appears. In the quasilinear case, $\psi_{s}$ is equal to one. When risk aversion is introduced, the stochastic process $\left\{\beta^{t} \psi_{t}\right\}_{t \geq 0}$ represents the intertemporal prices the government would be willing to pay for additional resources at different dates. The process $\left\{\frac{\psi_{t}}{u_{c, t}}\right\}_{t \geq 0}$ converts these prices in consumption equivalent units. The presence of $\psi_{s}$ is natural since taxes on capital affect capital accumulation and hence resources available.

The second term $T^{i}$ is the "intertemporal" term and corresponds to the traditional motive for

\footnotetext{
${ }^{10}$ The superscrpits "h", "i" and "b" stand respectively for "hedging", "intertemporal" and "bounds".
} 
capital taxation: The government can induce intertemporal resource transfers by affecting capital accumulation through capital taxation to reduce the burden taxation. The formula calls for subsidizing capital between $t$ and $t+1$ when resources are expected to be scarcer at $t+1$ than at $t-$ i.e. when $\frac{\psi_{t+1}}{u_{c, t+1}}$ is expected to be larger on average than $\frac{\psi_{t}}{u_{c, t}}-$ especially if the net marginal product of capital $1+\left(1-\tau_{t+1}^{k}\right) F_{k, t+1}$ or marginal utility $u_{c, t+1}$ is positively correlated with $\frac{\psi_{t+1}}{u_{c, t+1}}$.

This formula (28) for $\tau^{k}$ is valid under complete markets, with the only difference that $\nu_{s}$ is constant. Under complete markets, $T^{h}$ is equal to zero, but not $T^{i}$ in general. The well known case where taxes on capital are zero under complete markets is the case of CRRA preferences, separable between consumption and leisure. Indeed, under complete markets,

$$
\frac{\psi_{s}}{u_{c, s}}=1+\nu \frac{c_{s} u_{c c, s}}{u_{c, s}}-\frac{u_{c l, s}}{u_{c, s}} l_{s}
$$

so that if $u(c, l, s)=\frac{c^{1-\sigma}-1}{1-\sigma}+H(l, s)$,

$$
\frac{\psi_{s}}{u_{c, s}}=1-\nu \sigma
$$

is constant along the optimal path, and $T^{i}$ is equal to zero from period 2 on.

When markets are incomplete, $\frac{\psi_{s}}{u_{c, s}}$ is not constant anymore at a Ramsey outcome when preferences are CRRA and separable, so that $T^{i}$ is not equal to zero even in this particular case: At the Ramsey outcome, the government would be willing to pay a different price - in consumption equivalent units - for additional resources at different dates and in different states, so that the traditional motive for capital taxation remains. In fact, as already mentioned, the zero capital taxation result under CRRA and separable preferences is an application of the uniform commodity taxation result of Atkinson and Stigitz (1972). This result relies crucially on the assumption of complete markets.

The last term $T^{b}$ imparts a role for relaxing debt limits to capital taxes. For example, if the maximum debt limit is increasing in the capital stock in the economy, it is optimal to subsidize capital when the limit is binding to relax this constraint and allow for more debt accumulation. This term is zero if the imposed debt limits do not depend on capital. Note that this term would have been present in (22) if I had allowed debt limits to depend on capital.

The case where the production function is Cobb Douglas still provides a useful benchmark.

Proposition 3 If $F$ is Cobb Douglas, then $T_{t}^{h}=0$. for $t \geq 1$.

As in the quasi-linear case, $T^{h}$ is zero as soon as the need for hedging disappears.

Remark 4 If the Markov process $\left\{s_{t}\right\}_{t \geq 0}$ enters an absorbing state at $t_{0}$, then $T_{t}^{h}=0$ for $t \geq t_{0}+1$.

Remark 5 As in the quasi-linear case, equation (28) and Proposition 3 are valid irrespective of the asset structure of the economy.

It is also possible to give a characterization of $T^{i}$ along the lines of Zhu (1992). 
Assumption 2 The stochastic process $x_{t}=\left\{k_{t}, \tilde{b}_{t}, u_{c, t}, s_{t}\right\}$ is a stationary, ergodic, first order Markov process on a compact set $X^{\infty}$ : There exists a probability measure $P^{\infty}$ on a compact set $X^{\infty}$ such that for all $t$, and measurable set $A$,

$$
\begin{gathered}
\operatorname{Pr}\left\{x_{t} \in A\right\}=P^{\infty}\{A\} \\
\lim _{j \rightarrow \infty} \operatorname{Pr}\left\{x_{t+j} \in A \mid x_{t}\right\}=P^{\infty}\{A\}
\end{gathered}
$$

Assumption 3 The policy functions in (10) - including the multipliers - are continuous and for every closed set $A \subseteq X^{\infty}$, and $t>0, \operatorname{Pr}\left\{x_{t} \in A \mid x_{0}=x\right\}$ is continuous in $x$.

Assumption $4 P^{\infty}\left\{1+\left(1-\tau^{k}\right) F_{k, t}>0\right\}=1$.

Proposition 4 If assumptions 2, 3 and 4 hold, then one of the following holds: (i) $P^{\infty}\left\{T_{t}^{i}=0\right\}=$ 1; (ii) $P^{\infty}\left\{T_{t}^{i}>0\right\}>0$ and $P^{\infty}\left\{T_{t}^{i}<0\right\}>0$.

This proposition shows, that the insights of Zhu (1992) are still valid for the traditional motive for capital taxation embodied in $T^{i}$. At a stochastic steady state, $T^{i}$ cannot be always positive or always negative.

\section{Capital Ownership and the Structure of Government Li- abilities}

So far, I have restricted the government to trade only a risk free bond with consumers, whereas consumers faced a non-trivial portfolio decision in allocating their savings between government debt and capital. Preventing the government from trading on capital is without loss of generality under complete markets. But in environments with incomplete markets, this arbitrary restriction regains bite. Allowing the government to trade on the capital gives the government more ways to smooth taxes across time and states, and to hedge government expenditure shocks.

As we already mentionned, another way to interpret trading is that it allows the government to tax capital excess returns. This form of non-linear capital taxation is non-distorsionary and offers the same hedging benefits as a non-trivial position on the stock market.

\subsection{The Government Capital Asset Pricing Model}

I now remove this restriction. To illustrate that physical capital is an asset among others that the government can trade with consumers, I also introduce exogenous assets indexed by $i \in \mathbb{I}_{s_{-}}$. The subscript $s_{-}$allows for the possibility to let the investment opportunity set formed by the exogenous assets to vary with the state variable $s$.

I now allow the government and consumers to trade three kinds of assets: (i) a risk free bond; (ii) capital - an asset whose return in state $s$ is $1+\left(1-\tau^{k}\right) F_{k, s}$; (iii) and $\# \mathbb{I}_{s_{-}}$assets in zero net 
supply indexed by $i \in \mathbb{I}_{s_{-}}$- whose return in state $s$ when the shock in the previous period was $s_{-}$ is $R_{s}^{i, s_{-}}$.

Generically, if the number of traded assets is less than the number of shocks, markets are truly incomplete and the complete markets Ramsey outcome is not attainable. I will maintain this assumption throughout.

It is easy to see that the planning problem is still recursive with the same state variables $k, \tilde{b}, \theta, s_{-}$, where $\tilde{b}$ is now the value of the government's net financial position vis-a-vis the private sector. Denoting by $x_{i}$ government's holdings of asset $i \in \mathbb{I}_{s_{-}}$and by $k_{g}$ government's holdings of capital, the government's value function satisfies a modified version of (10):

\section{Bellman equation 2'}

$$
\tilde{V}\left(k, \tilde{b}, \theta, s_{-}\right)=\max \mathbb{E}\left\{u_{s}+\beta \tilde{V}\left(k_{s}^{\prime}, \tilde{b}_{s}^{\prime}, u_{c, s}, s\right) \mid s_{-}\right\}
$$

subject to

$$
\begin{gathered}
\mathbb{E}\left\{\beta u_{c, s}\left[1+\left(1-\tau^{k}\right) F_{k, s}\right] \mid s_{-}\right\}=\theta \\
\mathbb{E}\left\{\beta u_{c, s} R_{s}^{i, s_{-}} \mid s_{-}\right\}=\theta \\
\sum_{i \in \mathbb{I}_{s-}} x_{i}\left(R_{s}^{i, s_{-}}-\frac{\theta}{\beta \mathbb{E}\left\{u_{c, s}\right\}}\right) u_{c, s}+k_{g}\left(1+\left(1-\tau^{k}\right) F_{k, s}-\frac{\theta}{\beta \mathbb{E}\left\{u_{c, s}\right\}}\right) u_{c, s}+\tilde{b} \frac{u_{c, s}}{\beta \mathbb{E}\left\{u_{c, s}\right\}}+g_{s} u_{c, s} \\
\leq l_{s} F_{l, s} u_{c, s}+l_{s} u_{l, s}+\tau^{k} k F_{k, s} u_{c, s}+\tilde{b}_{s}^{\prime}, \quad \forall s \in \mathbb{S} \quad \forall s \in \mathbb{S} \\
c_{s}+g_{s}+k_{s}^{\prime} \leq F_{s}+k, \quad \forall s \in \mathbb{S} \\
\left.\underline{M}\left(k_{s}^{\prime}, u_{c, s}, s\right) \leq \tilde{b}_{s}^{\prime} \leq \bar{M}\left(k_{s}^{\prime}, u_{c, s}, s\right), \quad \forall 1\right) \quad(34)
\end{gathered}
$$

There are two differences between (10) and (29). First, there is now one Euler equation for each exogenous asset (31). The second difference is in the budget constraint of the government (32), where the total liability the government has to repay or refinance in state $s$ is now

$$
\sum_{i \in \mathbb{I}_{s_{-}}} x_{i}\left(R_{s}^{i, s_{-}}-\frac{\theta}{\beta \mathbb{E}\left\{u_{c, s} \mid s_{-}\right\}}\right)+k_{g}\left(1+\left(1-\tau^{k}\right) F_{k, s}-\frac{\theta}{\beta \mathbb{E}\left\{u_{c, s} \mid s_{-}\right\}}\right)+\tilde{b} \frac{1}{\beta \mathbb{E}\left\{u_{c, s} \mid s_{-}\right\}}
$$

The government therefore faces a non-trivial portfolio decision. It must decide not only the level but also the composition of its liabilities.

As is clear from (29), introducing more assets only relaxes the constraints in the planning problem. Therefore, as in the quasi-linear case, introducing more traded assets, or allowing the government to trade capital, improves the Ramsey outcome.

Remark 6 Expanding the set of assets the government can trade with consumers improves the Ramsey outcome

Here, more traded assets only give the government more flexibility to smooth distortionary taxes. 
This result hinges crucially on the absence of consumer heterogeneity. In this case, the introduction of additional traded assets would impose new constraints since heterogenous agents will generally engage in trades between themselves - which could potentially render the task of the planner more difficult.

Assuming an interior solution exists and that debt limits do not bind in state $s_{-}$, the following set of first order conditions characterize the optimal asset and liability structure of the government. For this, it is convenient to label the risk free rate $R^{s_{-}} \equiv \frac{\theta}{\beta \mathbb{E}\left\{u_{c, s} \mid s_{-}\right\}}$.

$$
\begin{gathered}
\mathbb{E}\left\{\beta R^{s_{-}} u_{c, s} \nu_{s} \mid s_{-}\right\}=\theta \nu_{s_{-}} \\
\mathbb{E}\left\{\beta\left[1+\left(1-\tau^{k}\right) F_{k, s}\right] u_{c, s} \nu_{s} \mid s_{-}\right\}=\theta \nu_{s_{-}} \\
\mathbb{E}\left\{\beta R_{s}^{i, s_{-}} u_{c, s} \nu_{s} \mid s_{-}\right\}=\theta \nu_{s_{-}}
\end{gathered}
$$

These equations form the government counterpart of the standard CCAPM Euler equations: I refer to them as the Government Capital Asset Pricing Model (GCAPM). Assets that pay well in states of the world where government funds are scarce require a lower expected rate of return, as can be seen for example from rewriting (37) in the following way

$$
\mathbb{E}\left\{R_{s}^{i, s_{-}} \mid s_{-}\right\}=R^{s_{-}}-\frac{\operatorname{Cov}\left\{R_{s}^{i, s_{-}}, u_{c, s} \nu_{s} \mid s_{-}\right\}}{\mathbb{E}\left\{u_{c, s} \nu_{s} \mid s_{-}\right\}}
$$

Equations (35), (36) and (37) hold together with the standard CCAPM Euler equations

$$
\begin{gathered}
\mathbb{E}\left\{\beta R^{s_{-}} u_{c, s} \mid s_{-}\right\}=\theta \\
\mathbb{E}\left\{\beta\left[1+\left(1-\tau^{k}\right) F_{k, s}\right] u_{c, s} \mid s_{-}\right\}=\theta \\
\mathbb{E}\left\{\beta R_{s}^{i, s_{-}} u_{c, s} \mid s_{-}\right\}=\theta
\end{gathered}
$$

Equations (35), (36) and (37) show that $\left\{\beta^{t} u_{c, t} \nu_{t}\right\}_{t \geq 0}$ can be thought of a pricing kernel for the government. This pricing kernel applies to assets traded with consumers - which is the case for all assets considered so far. It characterizes the price the government is willing to pay for an asset trade with consumers. Note that the result that $\nu_{s}$ is a risk adjusted martingale is simply a restatement of (35).

If consumers are not on the other side of the trade, the pricing kernel $\left\{\beta^{t} u_{c, t}\left(\nu_{t}+\frac{\psi_{t}}{u_{c, t}}\right)\right\}_{t \geq 0}$ is different and involves the shadow costs of resources $\psi_{t}$. Indeed, the price the government would be willing to pay for a non traded investment project paying out $X_{s}$ in state $s$ is

$$
\frac{\mathbb{E}\left\{X_{s} u_{c, s}\left(\nu_{s}+\frac{\psi_{s}}{u_{c, s}}\right) \mid s_{-}\right\}}{\nu_{s-}+\frac{\psi_{s-}}{\theta}}
$$


It should also be emphasized that the results on capital taxation still hold when more traded assets are introduced. In particular, taxes are still given by (28). The only difference is in the hedging term: the elasticity of capital to the tax rate has to be replaced by the elasticity of the part of the capital stock held by the private sector to the tax rate

$$
\frac{\mathbb{E}\left\{-\left(k-k_{g}\right)\left(1-\tau^{k}\right) F_{k k, s} u_{c, s} \mid s_{-}\right\}}{\mathbb{E}\left\{F_{k, s} u_{c, s} \mid s_{-}\right\}}
$$

The GCAPM, together with the CCAPM, provides a simple and powerful framework for addressing the optimal liability structure of the government in various contexts. In ongoing work, Farhi and Werning (2005) study the optimal maturity structure of government debt when the government is restricted to issue only risk-free debt of a limited number of maturities.

\subsection{The GCAPM in The Quasi-Linear Case}

I consider here the case where preferences are quasi-linear. This stripped down setup will allow me to derive stark results on the optimal structure of government liabilities.

As in the previous subsection, I allow the government and consumers to trade three kinds of assets: (i) a risk free bond; (ii) capital - an asset whose return in state $s$ is $1+\left(1-\tau^{k}\right) F_{k, s}$; (iii) and $\# \mathbb{I}_{s_{-}}$assets in zero net supply indexed by $i \in \mathbb{I}_{s_{-}}$- whose return in state $s$ when the shock in the previous period was $s_{-}$is $R_{s}^{i, s_{-}}$. The definitions of feasible allocations, competitive equilibria and Ramsey outcomes can be straightforwardly extended to this new setup.

It is easy to see that the planning problem is still recursive with the same state variables $\tilde{b}$ and $s_{-}$, where $\tilde{b}$ is now the value of the government's net financial position vis-a-vis the private sector. Denoting by $x_{i}$ government's holdings of asset $i \in \mathbb{I}_{s_{-}}$and by $k_{g}$ government's holdings of capital, the government's value function satisfies a modified version of (15) analogous to (32).

\section{Bellman equation 3'}

$$
\tilde{V}\left(\tilde{b}, s_{-}\right)=\max \mathbb{E}\left\{F_{s}+k\left(1-\frac{1}{\beta}\right)-g_{s}+\beta \tilde{V}\left(\tilde{b}_{s}^{\prime}, s\right) \mid s_{-}\right\}
$$

subject to

$$
\begin{gathered}
\mathbb{E}\left\{\beta\left[1+\left(1-\tau^{k}\right) F_{k, s}\right] \mid s_{-}\right\}=1 \\
\mathbb{E}\left\{\beta R_{s}^{i, s_{-}} \mid s_{-}\right\}=1 \quad \forall i \in \mathbb{I}_{s_{-}} \\
\sum_{i \in \mathbb{I}_{s_{-}}} x_{i}\left(R_{s}^{\left.i, s_{-}-\frac{1}{\beta}\right)+k_{g}\left(1+\left(1-\tau^{k}\right)\right.} F_{k, s}-\frac{1}{\beta}\right)+\tilde{b} \frac{1}{\beta}+g_{s} \leq l_{s} F_{l, s}+l_{s} H_{l, s}+\tau^{k} k F_{k, s}+\tilde{b}_{s}^{\prime}, \quad \forall s \in \mathbb{S} \\
\underline{M}_{s} \leq \tilde{b}_{s}^{\prime} \leq \bar{M}_{s}, \quad \forall s \in \mathbb{S}
\end{gathered}
$$

To make the comparison with (32), I have left as constraints in the program the conditions $\mathbb{E}\left\{\beta R_{s}^{i, s_{-}} \mid s_{-}\right\}=1$ which do not depend on the allocation when the marginal utility of consumption 
is constant, and are just in this case exogenous conditions that need to be met for an equilibrium to exist.

In a particular case, allowing the government to trade physical capital actually allows its to reach the complete markets Ramsey outcome.

Proposition 5 Absent productivity and preference shocks, the government can perfectly approximate the complete markets Ramsey outcome with a larger and larger long or short position in capital.

The intuition for this proposition is that absent productivity and preference shocks, the complete markets Ramsey outcome features constant labor supply across states. Hence the return on physical capital is risk free: physical capital and the risk free bond are colinear assets. By commanding small deviations from the constant level labor supply of the complete markets allocation, the government can align the variations of the returns on capital with its need for funds. By taking extreme positions in capital, compensated by opposite positions on the risk free bond, the government can then leverage these variations and smooth perfectly its need for funds across states.

The extreme positions required for replicating the complete markets allocation are reminiscent of the findings of Angeletos (2002) and Buera and Nicolini (2004). Both contributions analyze how the government can use different maturities of risk free debt to implement complete markets Ramsey outcome. They find that generically, if the number of maturities is larger than the number of shocks, then the complete markets allocation can be implemented, but that typically, very large positions in the different maturities are required. It is also worth noting that in this example with quasi-linear preferences, different maturities of risk free debt would not permit the government to replicate the complete markets Ramsey outcome since the entire term structure is entirely pinned down by preferences.

With productivity and preferences shocks, the government can typically no longer replicate the complete markets Ramsey outcome if fewer assets than states of the world are traded. The GCAPM takes the particularly simple form ${ }^{11}$

$$
\begin{gathered}
\mathbb{E}\left\{\left[1+\left(1-\tau^{k}\right) F_{k, s}-R\right] \nu_{s} \mid s_{-}\right\}=0 \\
\mathbb{E}\left\{\left[R_{s}^{i, s_{-}}-R\right] \nu_{s} \mid s_{-}\right\}=0
\end{gathered}
$$

where $R \equiv \frac{1}{\beta}$ is the risk free rate.

Equations (43) and (44) can be compared to the standard CCAPM Euler equations

$$
\begin{gathered}
\mathbb{E}\left\{1+\left(1-\tau^{k}\right) F_{k, s}-R \mid s_{-}\right\}=0 \\
\mathbb{E}\left\{R_{s}^{i, s_{-}}-R \mid s_{-}\right\}=0
\end{gathered}
$$

\footnotetext{
${ }^{11}$ I choose to write the GCAPM and CCAPM equations in this "excess return" format to allow for easier comparison with Bohn (1990).
} 
which characterize the optimal portfolio for consumers. The only difference between the two sets of equations is that the marginal utility of consumption, 1 , is replaced by $\nu_{s}$ - the multiplier measuring the severity of the government budget constraint in state $s$. The stochastic process $\left\{\beta^{t}\left(1+\nu_{t}\right)\right\}_{t \geq 0}$ can be interpreted as the pricing kernel of the government. A way to see this is to introduce, instead of assuming an exogenous process for government expenditures, a standard utility for government funds $v\left(g_{t}, s_{t}\right)$. In this case, the first order condition for government expenditures is $v_{g}\left(g_{t}, s_{t}\right)=1+\nu_{t}$.

Note that the pricing kernel of the government is not trivial - i.e. has a positive variance despite the face that agents are risk neutral. The variation in the pricing kernel comes only from the imperfect ability to smooth taxes across time under incomplete markets. Indeed, if markets were complete, the pricing kernel of the government and the pricing kernel of the agents would be colinear - in this instance, constant.

These equations can be compared to the results in Bohn (1990). Following Barro (1979), Bohn considers an environment with incomplete markets, no capital and risk neutral consumers, where the government must finance an exogenous stream of expenditures using distortionary taxes. Taxes $\tau$ are assumed to impose an ad hoc increasing convex deadweight cost $h(\tau)$. Bohn derives the following formula for the return of any traded asset $R$

$$
\mathbb{E}\left\{\left[R_{t}-R\right] h^{\prime}\left(\tau_{t}\right)\right\}=0
$$

Hence (44) can be seen as a microfounded version of (45). Some important differences are worth noting. In particular it is not generally true in my model that $\nu_{t}$ is a function of $\tau_{t}^{l}$ and $\tau_{t}^{k}$ or even of tax revenues, as a perfect analogy with (45) would require. In fact, $\nu_{t}$ is a function of the $\# \mathbb{S}^{2}+1$ variables $s_{t}, s_{t-1}$ and $\widetilde{b}_{t-1}$. Generically, $\nu_{t}$ is therefore not a function of the $\# \mathbb{S}+1$ functions $\tau_{s}^{l}$ and $\tau^{k}$. In the specification with a utility $v\left(g_{t}, s_{t}\right)$ from government expenditures, $\nu_{t}=v_{g}\left(g_{t}, s_{t}\right)-1$, so that $\nu_{t}$ is a function of $g_{t}$ and $s_{t}$ - which can be expressed as a function of $s_{t-1}, s_{t}$ and $\widetilde{b}_{t-1}$. Importantly, the state $s_{t}$ appears in this formula along with government expenditures. Even if I were to assume that $v\left(g_{t}, s_{t}\right)$ is independent of $s_{t}$, this discussion would suggest that a non linear function of government expenditures $v_{g}\left(g_{t}\right)-1$ is better suited for approximating the marginal cost of public funds that an increasing function of taxes or tax revenues $h^{\prime}\left(\tau_{t}\right)$ as in (45). This discussion is important, as tests and implications of this theory rely crucially on sorting out correctly the time series properties of the pricing kernel of the government.

I have focused so far on traded assets. Uncovering the pricing kernel of the government allows me to determine the price the government would be willing to pay for non traded assets. In particular, consider a marginal public investment project requiring an outlay $I$, and whose payoff $X_{s}$ is not spanned by traded assets. Then the government should follow the following capital budgeting rule: invest in the project if and only if

$$
\frac{\mathbb{E}\left\{X_{s} \mid s_{-}\right\}}{R-\frac{\operatorname{Cov}\left\{X_{s} / I, 1+\nu_{s} \mid s_{-}\right\}}{1+\mathbb{E}\left\{\nu_{s} \mid s_{-}\right\}}} \geq I
$$


where $R=\frac{1}{\beta}$. This capital budgeting rule (46) shows that the government should discount cash flows using the beta associated with its own pricing kernel, and not with that of consumers. Hence the government should attach a public risk premium to returns that covary negatively with shocks affecting adversely its budget.

It is interesting to note that the asset holdings in the optimal portfolio of government liabilities $\left\{x_{t}^{i}, k_{g, t}\right\}$ has a unit root component. Hence not only do the government's total liabilities $\tilde{b}_{t}$ have a random walk component, but the composition of its liabilities display a similar kind of persistence.

\section{Numerical Simulations}

\subsection{Numerical method and parameter values}

Numerical method. I approach the problem by solving the dynamic programming problems (10), (29), (15) and (38), and then back out the optimal policies. In my calculations, I restrict the state space to be rectangular and bounded. I check numerically that enlarging the rectangle doesn't alter the results. The dynamic programming problem is then solved by a value iteration algorithm with Howard acceleration. I approximate the value function with cubic splines.

Calibration of the risk averse case. To permit comparability of my results to those in Chari, Christiano and Kehoe (1994), I consider the same parameters and functional forms. I assume that preferences are of the form

$$
u(c, l)=(1-\gamma) \log (c)+\gamma \log (1-l)
$$

Technology is described by a production function

$$
F(k, l, z, t)=k^{\alpha}(\exp (\rho t+\tilde{z}) l)^{1-\alpha}-\delta k
$$

This incorporates two kinds of labor augmenting technological change in the production function. The variable $\rho$ captures deterministic growth in this technical change. The variable $\tilde{z}$ is a zero mean technological shock that follows a two-state Markov chain with mean $\bar{z}$ and autocorrelation $\rho_{z}$. Let government expenditure be given by $g_{t}=G \exp (\rho t+\tilde{g})$ where $G$ is a constant and $\tilde{g}$ follows a two-state Markov chain with mean $\bar{g}$ and autocorrelation $\rho_{g}$. I take $\gamma=0.75, \beta=0.98, \alpha=0.34$, $\rho=0.016, G=0.07, \rho_{g}=0.89, \sigma_{g}=0.07, \rho_{z}=0.81$ and $\sigma_{z}=0.04$.

I impose fixed debt limits $\underline{M}=-0.2 \overline{G D P}^{f b}$ and $\bar{M}=\overline{G D P}^{f b}$, where $\overline{G D P}^{f b}$ is the mean across states of first best level of GDP that would occur if the state were absorbing.

Notice that without technological shocks, the economy has a balanced growth path along which consumption, capital and government spending grow at rate $\rho$ and labor is constant. As in Chari, Christiano and Kehoe (1994), it is straightforward to modify the model to allow for exogenous growth. 
The length of the accounting period where capital are held fixed by assumption is an important parameter. I analyze two series of simulations, one where the period length is one year, and one where the period length is five years.

Calibration of the quasi-linear case. I also calibrate a model with quasi-linear preferences given by

$$
u(c, l)=c+\gamma \log (1-l)
$$

To ensure that labor is stationary, I impose that growth is zero in this case. I also adjust $\gamma$ to 0.5 .

\subsection{Results}

Results in the quasi-linear case. Figure 1 displays several variables along a typical path, in an economy with only government expenditure shocks and no capital ownership. The top left panel displays the path of shocks, which take only two possible values, one and two, corresponding to low and high expenditures respectively. Note that debt, labor taxes, labor and capital all appear to be more persistent than the shock process, reflecting the fact that they incorporate a random walk component. The bottom left panel represents taxes on capital. Taxes on capital are negative - as predicted by Proposition $2-$ but are never larger than $10^{-5}$. I experimented with other specifications of the production function (CES) and never got a result larger than $10^{-4}$. Note that capital taxes also seem to incorporate some persistence, although less than other variables in the economy. Capital taxes are relatively larger in absolute value when debt approaches its upper limit.

Figure 2 (respectively 3) displays the policy functions when the previous government expenditure shock was low (respectively high). On the horizontal axis of every graph is inherited debt. On the vertical axis is the variable whose name indexes the graph. The solid blue (respectively dashed green) lines correspond to the policy functions when the contemporaneous shock is low (respectively high). The second graph on the top row is a zoom on the top left graph representing the policy functions for debt. The thick red line is the 45 degree line. As is apparent from this graph, a high shock is partially absorbed through an increased debt, and a low shock through a decrease in debt. The bottom left graph displays the policy functions for the multipliers. Both are increasing in the level of inherited debt. The multiplier associated with the high shock is always larger than the multiplier associated with the low shock. Moreover, the bottom right panel shows that the variance of $\nu_{s}$ across states for a given $s_{-}$is increasing in the level of inherited debt: As inherited debt gets close to the upper debt limit, the government is more limited in its ability to use debt as a shock absorber if the high shock hits. Note that this variance is always minuscule here, reflecting the fact that with reasonable debt limits, risk free debt is a very good shock absorber. Capital taxes are small for two reasons: First because of the Cobb Douglas benchmark, second because the variance of $\nu_{s}$ is small. As government debt approaches the upper limit, the variance of $\nu_{s}$ increases and with it the absolute value of the tax rate.

Table 1 displays the optimal capital ownership level in the invariant distribution, depending on the environment. I first discuss the results when the period length is set to one year. With only 
government expenditure shocks, Proposition 5 shows that the government takes an infinite long or short position in capital and replicates the complete markets allocation. With only two possible productivity shocks, the government can also replicate the complete markets allocation, with a finite - but large - short position of $-295 \%$ of $\bar{k}^{f b}$, where is the mean across states of first best level of capital that would prevail if the state were absorbing. That a short position is required is easily understood: The marginal product of capital correlates positively with productivity shocks, and hence with government revenues. The magnitude of the position results from the fact that capital is very colinear with risk free debt. Hence a large leveraged position, short in capital, long in the risk free bond, is required to provide the government with a state contingent source of revenues that matches the desired variations in the net present value of government surpluses. With government expenditure shocks and productivity shocks, the government cannot replicate the complete markets allocation anymore. The optimal government capital ownership level is almost identical to the one that prevails with only technological shocks. This reflects the fact that in this business cycle calibration, technological shocks are a bigger source of variation in the government needs for funds than government expenditure shocks.

Increasing the period length to five years does not alter the result of Proposition 5. By contrast, optimal government capital ownership in the case of productivity shocks, or both productivity shocks and government expenditure shocks drops from $-295 \%$ to $-59 \%$. The reason is that as the period length is increased, shocks per period become less persistent - getting closer and closer to i.i.d. Hence the variation of the net present value of government surpluses that the government seeks to hedge becomes smaller - approximately 5 times smaller. Hence a smaller position in capital is required.

In this model, the welfare gains from completing markets are small. In all simulations, I compute them to be less than $0.01 \%$ of lifetime consumption. This confirms the finding of AMSS for business cycle type calibrations. The size of welfare gains is well understood from AMSS: They depend on the size and persistense of the shocks, the curvature in the uitlity function, and the debt limits. The welfare gains are much larger in a war and peace exercise I report below. Nevertheless, an interesting question is: How much of the gap between welfare in the incomplete markets, no government ownership allocation and welfare in the complete markets allocation can government ownership cover? In all simulations, I find this number to be above $85 \%$. Moreover, in the simulation with a 5 year period length and both government and productivity shocks, I find that a short position of $15 \%$ of $\bar{k}^{f b}$ allows to realize $47 \%$ - a large, but more reasonable position- of these welfare gains.

I also calibrate a war and peace example, with a one year period length and only government expenditure shocks. The parameters are the same as in the business cycle simulation, except for $\sigma_{g}$ which I take to be equal to 0.7 instead of 0.07 . I compute the mean welfare gains to be $0.6 \%$ of lifetime consumption. The welfare gains reach $1.5 \%$ of lifetime consumption if debt is close to the debt limit and the economy experienced a high government expenditure shock in the previous period. With such large shocks, taxes on capital are larger in absolute value than in the businesscycle simulations, but small - between 0 and $-1 \%$ with probability $75 \%$. Taxes on capital become 
large - up to $-20 \%$ - when debt is very close to the debt limit.

Results in the risk averse case. I first start with a limited experiment: I start the economy in period 0 with a given value of $\left(b_{0}, k_{0}, \theta_{0}, s_{-}\right)$with $s_{-}=1$, corresponding to the low government expenditure shock. In period 1, a permanent government expenditure shock hits the economy. This shock can be high - correpsonding to $s=2$ - or low - corresponding to $s=1$ - with probabilities $5 \%$ and $95 \%$ respectively. Capital ownership by the government is disallowed. All the uncertainty in the economy is resolved in period 1. Figures 4 and 5 display the impulse responses of several variables in the economy corresponding to the high and low shock respectively.

First note that the hedging term is non-zero only in the first period, and is smaller than $10^{-3}$. Hence taxes on capital are dominated by the intertemporal term. Following a high shock, taxes on capital spike at $150 \%$ and then fall back to 0 . The interest rate drops to $-2 \%$ and then reverts almost immediately to $2 \%$. This effect would be present even in an economy without capital as in AMSS. Werning (2005) coins the term "interest rate manipulation".

Debt initially goes up to absorb the high government expenditure shock in period 1, and then drops permanently to a level lower than $b_{0}$. From the government's budget constraint, it is apparent that this is the mechanical result of the spike in capital taxation revenues and the low interest rate that prevails between period 1 and period 2. The lower post period 2 debt level helps reduce the burden of interest payments on the government's budget constraint. Capital taxes therefore play a important role in absorbing the shock: They help reduce the debt burden after a high shocks both by lowering the interest rate and by directly collecting revenues. Note that in the case where the low shock hits, capital is subsidized between period 1 and period 2. Capital taxes are therefore not used to raise revenues on average, but rather to help absorb the variations in the net present value of government expenditures.

Consumption initially increases. This is just an intertemporal substitution effect as consumers face a low interest rate between period 1 and period 2 . From period 2 on, consumption is permanently lower. Labor and labor taxes also move up permanently after period 2 , hinting at the random walk properties of these variables. The fact that labor and labor taxes increase is just the result of a wealth effect, as consumption drops after period 2. Capital drops after the shock. From the resource constraint, one can see that this drop in investment is the mirror image of the increase in consumption stemming from interest rate manipulation and the increase in government expenditure.

Figures 6 and 7 display impulse responses for a similar exercise with respectively a low and high productivity shock. The technological shock inperiod 1 can be low - correpsonding to $s=2-$ or high - corresponding to $s=1$ - with probabilities $5 \%$ and $95 \%$ respectively.

Figure 8 displays a typical path for several variables in an economy with only government expenditure shock and no capital ownership. After a transition from a low shock to a high shock, the tax on capital spikes at about $200 \%$ and then reverts to a level of about $5 \%$. That taxes on capital are positive until a new low shock hits reflects the fact that resources are scarcer today than tomorrow on average, given the possibility that a low shock occurs. Symmetrically, after a transition from a high shock to a low shock, the tax on capital spikes at about $-200 \%$ and then 
reverts to a level of about $-5 \%$.

The volatility of capital taxes depends crucially on the period length. The reason can be explained as follows. Ultimately, the welfare costs associated with capital taxes come through the distortion that they impose on the path of consumption. The distortion associated with a one time capital tax becomes larger as the period length is increased, because consumption is distorted for a longer period. By contrast, the benefits in terms of reduced debt following a high shock decrease as shocks become less persistent per period. In the continuous time limit, the costs are zero, and the government is able to replicate the complete markets allocation with infinite taxes or subsidizes during an infinitely small period following the shock.

Figure 9 displays a typical path for several variables in the economy when the period length is set to five years. The positive and negative spikes in capital taxes are now $20 \%$ and $-20 \%$. Table 2 summarizes the statistical properties of capital and labor taxes depending on the period length. Standard deviations and autocorrelations are reported per period and not per year. The standard deviation of labor taxes $-5.1 \%$ - is close to the number reported by Chari, Christiano and Kehoe (1994) -6\%-for this case. Labor taxes are quite persistent, and more persistent when the period length is 5 years: this is the consequence of less abrupt movements in capital taxes and the capital stock when the period length is longer. Importantly, note that capital taxes hardly display any persistence. This is due to the fact that the magnitudes of capital taxes is essentially by a difference term $\frac{\psi_{s}}{u_{c, s}}-\frac{\psi_{s-}}{\theta}$, which tends to remove the unit root component in $\frac{\psi_{s}}{u_{c, s}}$.

For an economy with only two government expenditure shocks and a one year period length, the government can replicate the complete markets allocation with a capital ownership of about $2300 \%$ of $\bar{k}^{f b}$. This position drops to $680 \%$ of $\bar{k}^{f b}$ when the period length is extended to five years. For an economy with only two productivity shocks and a one year period length, the government can replicate the complete markets allocation with a capital ownership of about $-400 \%$ of $\bar{k}^{f b}$. This position drops to $-157 \%$ of $\bar{k}^{f b}$ when the period length is extended to five years. The welfare gains from completing markets are small $-0.09 \%$ of lifetime consumption - albeit larger than in the quasi-linear case.

\section{Conclusion}

I have characterized optimal capital taxation and government ownership when markets are incomplete. In this context, capital taxation and ownership are two ways for the government to collect state dependent revenues and hedge its burden from distortionary taxation across states. Although I have focused on capital taxation, the insight that with incomplete markets and a policy lag, taxes acquire a direct hedging role, and that the indirect hedging consequences of the distortions they generate should be taken into account, is more general.

I have found that this hedging motive for capital taxation is always negligible: Capital taxes come with distortions through the adjustment of capital. This affects the capital tax base and labor tax revenues across states in a way that almost perfectly undoes the direct hedging benefits. In a 
baseline case, capital taxes are exactly zero. Away from this benchmark, the hedging component of capital taxes is always computed to be minuscule.

By contrast, capital ownership provides the government with a powerful hedging instrument. The reason is that trading, unlike taxing, does not involve distorsions. In a baseline case, I have shown that the government can perfectly approximate the complete markets allocation by taking an infinitely long or short position in capital. Away from this benchmark, optimal positions are large and decrease sharply when the period length is increased. Substantial benefits can be reaped from smaller positions. Government expenditure shocks call for a long position while productivity shocks push in the direction of a short position. In a business cycle calibration, I have shows that productivity shocks is the leading force - resulting in an optimal long position.

Refining these propositions would require developing a more realistic model for investment incorporating adjustment costs and time to build - and asset valuation. It would also be interesting to move away from the representative agent framework I have analyzed. Unobservable agent heterogeneity together with the government's concern for redistribution would provide an endogenous reason for the use distorsionary taxes. Finally, the large capital positions called for by the model put strain on the assumption of a benevolent government with full commitment. In this light, incorporating relevant political economy constraints into Ramsey type models of optimal taxation appears as a promissing research avenue. I leave these issues for future work.

\section{Appendix}

The three terms in (28)

The three terms in (28) are

$$
\tau^{k}=T^{h}\left(k, \tilde{b}, \theta, s_{-}\right)+T^{i}\left(k, \tilde{b}, \theta, s_{-}\right)+T^{b}\left(k, \tilde{b}, \theta, s_{-}\right)
$$

where

$$
\begin{aligned}
& T^{h}\left(k, \tilde{b}, \theta, s_{-}\right)=\frac{\frac{\mathbb{E}\left\{-k\left(1-\tau^{k}\right) F_{k k, s} u_{c, s} \mid s_{-}\right\}}{\mathbb{E}\left\{F_{k, s} u_{c, s} \mid s_{-}\right\}}}{\frac{\mathbb{E}\left\{F_{k, s} u_{c, s} \frac{\psi_{s}}{u_{c, s}} \mid s_{-}\right\}}{\mathbb{E}\left\{F_{k, s} u_{c, s} \mid s_{-}\right\}}+\frac{\mathbb{E}\left\{F_{k, s} \nu_{s} u_{c, s} \mid s_{-}\right\}}{\mathbb{E}\left\{F_{k, s} u_{c, s} \mid s_{-}\right\}}}\left[\frac{\operatorname{Cov}\left\{k F_{k, s} u_{c, s}, \nu_{s} \mid s_{-}\right\}}{\mathbb{E}\left\{k F_{k, s} u_{c, s} \mid s_{-}\right\}}-\frac{\operatorname{Cov}\left\{k F_{k k, s} u_{c, s}, \nu_{s} \mid s_{-}\right\}}{\mathbb{E}\left\{k F_{k k, s} u_{c, s} \mid s_{-}\right\}}\right] \\
& T^{i}\left(k, \tilde{b}, \theta, s_{-}\right)=-\frac{\frac{\mathbb{E}\left\{\left[1+\left(1-\tau^{k}\right) F_{k, s}\right] u_{c, s}\left(\frac{\psi_{s}}{u_{c, s}}-\frac{\psi_{s-}}{\theta}\right) \mid s_{-}\right\}}{\beta \mathbb{E}\left\{u_{c, s} F_{k, s} \mid s_{-}\right\}}}{\frac{\mathbb{E}\left\{F_{k, s} u_{c, s} \frac{\psi_{s}}{u_{c, s}} \mid s_{-}\right\}}{\mathbb{E}\left\{F_{k, s} u_{c, s} \mid s_{-}\right\}}+\frac{\mathbb{E}\left\{F_{k, s} \nu_{s} u_{c, s} \mid s_{-}\right\}}{\mathbb{E}\left\{F_{k, s} u_{c, s} \mid s_{-}\right\}}} \\
& T^{b}\left(k, \tilde{b}, \theta, s_{-}\right)=\frac{\frac{\frac{\nu_{2}, s_{-}}{\beta} \underline{M}_{k, s_{-}}-\frac{\nu_{1}, s_{-}}{\beta} \bar{M}_{k, s_{-}}}{\beta \mathbb{E}\left\{u_{c, s} F_{k, s} \mid s_{-}\right\}}}{\frac{\mathbb{E}\left\{F_{k, s} u_{c, s} \frac{\psi_{s}}{u_{c, s}} \mid s_{-}\right\}}{\mathbb{E}\left\{F_{k, s} u_{c, s} \mid s_{-}\right\}}+\frac{\mathbb{E}\left\{F_{k, s} \nu_{s} u_{c, s} \mid s_{-}\right\}}{\mathbb{E}\left\{F_{k, s} u_{c, s} \mid s_{-}\right\}}}
\end{aligned}
$$

where $\psi_{s-}$ is the multiplier on the resource constraint in the previous period. 


\section{Proof of Lemma 1}

The consumer's problem is a convex program, and $u$ and $F$ are not satiated. Then the first order conditions (6), (7) and (8) together with (5) holding with equality are necessary and sufficient for an optimum in the consumer's problem. It is straightforward to see that if (1) holds with equality, the fact that (3) holds with equality implies that (5) holds with equality - a version of Walras law.

\section{A derivation of (26) and (28) using a Lagrangian approach}

The approach in the text relies on the assumption that the value function is differentiable. An alternative to making that assumption is to approach the task of characterizing the Ramsey allocation by composing a Lagrangian for the Ramsey problem. I keep notations as close as possible to those in the text.

I attach stochastic processes $\left\{\beta^{t} \operatorname{Pr}\left(s^{t}\right) \mu_{t}, \beta^{t} \operatorname{Pr}\left(s^{t}\right) \nu_{t}, \beta^{t} \operatorname{Pr}\left(s^{t}\right) \nu_{1, t}, \beta^{t} \operatorname{Pr}\left(s^{t}\right) \nu_{2, t}, \beta^{t} \operatorname{Pr}\left(s^{t}\right) \psi_{t}\right\}_{t \geq 0}$ to the constraints

$$
\begin{gathered}
u_{c, t}=\mathbb{E}_{t}\left\{\beta u_{c, t+1}\left[1+\left(1-\tau_{t+1}^{k}\right) F_{k, t+1}\right]\right\}, \quad \forall t \geq 0 \text { and } s^{t} \in \mathbb{S}^{t}, \\
\tilde{b}_{t-1} \frac{u_{c, t}}{\beta \mathbb{E}_{t-1}\left\{u_{c, t}\right\}}+g_{t} u_{c, t} \leq l_{t} F_{l, t} u_{c, t}+l_{t} u_{l, t}+\tau_{t}^{k} k_{t-1} F_{k, t} u_{c, t}+\tilde{b}_{t}, \quad \forall t \geq 0 \text { and } s^{t} \in \mathbb{S}^{t}, \\
\underline{M}\left(k_{t}, u_{c, t}, s_{t}\right) \leq \tilde{b}_{t} \leq \bar{M}\left(k_{t}, u_{c, t}, s_{t}\right), \quad \forall t \geq 0 \text { and } s^{t} \in \mathbb{S}^{t} \text { and } \\
c_{t}+g_{t}+k_{t} \leq F_{t}+k_{t-1}, \quad \forall t \geq 0 \text { and } s^{t} \in \mathbb{S}^{t} .
\end{gathered}
$$

Then the Lagrangian for the Ramsey problem can be represented as

$$
\begin{aligned}
L\left(b_{-1}^{g}, r_{0}, k_{0}, \tau_{0}^{k}\right)= & \mathbb{E}_{-1} \sum_{t=0}^{\infty} \beta^{t} u_{t} \\
& \mathbb{E}_{-1} \sum_{t=0}^{\infty} \beta^{t}\left[-\mu_{t} u_{c, t}+\mu_{t-1} u_{c, t}\left(1+\left(1-\tau_{t}^{k}\right) F_{k, t}\right)\right] \\
& +\mathbb{E}_{-1} \sum_{t=0}^{\infty} \beta^{t} \nu_{t}\left(-\tilde{b}_{t-1} \frac{u_{c, t}}{\beta \mathbb{E}_{t-1}\left\{u_{c, t}\right\}}-g_{t} u_{c, t}+l_{t} F_{l, t} u_{c, t}+l_{t} u_{l, t}+\tau_{t}^{k} k_{t-1} F_{k, t} u_{c, t}+\tilde{b}_{t}\right) \\
& +\mathbb{E}_{-1} \sum_{t=0}^{\infty} \beta^{t}\left[\nu_{2, t}\left(\tilde{b}_{t}-\underline{M}\left(k_{t}, u_{c, t}, s_{t}\right)\right)+\nu_{1, s}\left(\bar{M}\left(k_{t}, u_{c, t}, s_{t}\right)-\tilde{b}_{t}\right)\right] \\
& +\mathbb{E}_{-1} \sum_{t=0}^{\infty} \beta^{t} \psi_{t}\left(F_{t}+k_{t-1}-c_{s}-g_{t}-k_{t}\right)
\end{aligned}
$$

where I have introduced for notational convenience the multiplier $\mu_{-1}$, which I impose to be zero: $\mu_{-1}=0$.

I am now in position to derive the first order conditions associated with this Lagrangian.

The first order condition for $\tilde{b}_{t}$ is

$$
\nu_{t}-\frac{\mathbb{E}_{t}\left\{u_{c, t} \nu_{t+1}\right\}}{\mathbb{E}_{t}\left\{u_{c, t}\right\}}+\nu_{2, t}-\nu_{1, t}=0
$$


which proves equation (26).

The formula for the optimal tax on capital (28) can be derived by combining the first order conditions for $\tau_{t}^{k}$ and $k_{t-1}$. The first order condition for $\tau_{t}^{k}$ can be written as

$$
-\mu_{t-1} \mathbb{E}_{t-1}\left\{u_{c, t} F_{k, t}\right\}+\mathbb{E}_{t-1}\left\{u_{c, t} k_{t-1} F_{k, t} \nu_{t}\right\}=0
$$

For $t \geq 1$, the first order condition for $k_{t-1}$ is

$$
\begin{aligned}
0= & \mu_{t-1} \mathbb{E}_{t-1}\left\{\beta u_{c, t}\left(1-\tau_{t}^{k}\right) F_{k k, t}\right\}+\mathbb{E}_{t-1}\left\{\beta \nu_{t}\left(l_{t} F_{k l, t} u_{c, t}+\tau_{t}^{k} F_{k, t} u_{c, t}+\tau_{t}^{k} k_{t-1} F_{k k, t} u_{c, t}\right)\right\} \\
& -\nu_{2, t-1} \underline{M}_{k, t-1}+\nu_{1, t-1} \bar{M}_{k, t-1}+\mathbb{E}_{t-1}\left\{\beta \psi_{t}\left(1+F_{k, t}\right)\right\}-\psi_{t-1}
\end{aligned}
$$

I use (47) to replace $\mu_{t-1}$. I then use the constant return to scale assumption to replace $l_{t} F_{k l, t}$ by $-k_{t-1} F_{k k, t}$, to rearrange (47) as follows

$$
\begin{aligned}
0= & \left(1-\tau_{t}^{k}\right) \frac{\mathbb{E}_{t-1}\left\{u_{c, t} k_{t-1} F_{k, t} \nu_{t}\right\}}{\mathbb{E}_{t-1}\left\{u_{c, t} F_{k, t}\right\}} \mathbb{E}_{t-1}\left\{\beta u_{c, t} F_{k k, t}\right\}+\tau_{t}^{k} \mathbb{E}_{t-1}\left\{\beta \nu_{t} F_{k, t} u_{c, t}\right\}-\left(1-\tau_{t}^{k}\right) \mathbb{E}_{t-1}\left\{\beta \nu_{t} k_{t-1} F_{k k, t} u_{c, t}\right\} \\
& +\tau_{t}^{k} \mathbb{E}_{t-1}\left\{\beta \psi_{t} F_{k, t}\right\}+\mathbb{E}_{t-1}\left\{\frac{\psi_{t}}{u_{c, t}} \beta\left(1+\left(1-\tau_{t}^{k}\right) F_{k, t}\right) u_{c, t}\right\}-\frac{\psi_{t-1}}{u_{c, t-1}} \mathbb{E}_{t-1}\left\{\beta\left(1+\left(1-\tau_{t}^{k}\right) F_{k, t}\right) u_{c, t}\right\} \\
& -\nu_{2, t-1} \underline{M}_{k, t-1}+\nu_{1, t-1} \bar{M}_{k, t-1}
\end{aligned}
$$

which in turn can be rewritten as

$$
\tau_{t}^{k}=T_{t}^{h}+T_{t}^{i}+T_{t}^{b}
$$

where

$$
\begin{gathered}
T_{t}^{h}=\frac{\frac{\mathbb{E}_{t-1}\left\{-k_{t-1}\left(1-\tau_{t}^{k}\right) F_{k k, t} u_{c, t}\right\}}{\mathbb{E}_{t-1}\left\{F_{k, t} u_{c, t}\right\}}}{\frac{\mathbb{E}_{t-1}\left\{F_{k, t} u_{c, t} \frac{\psi_{t}}{u_{c, t}}\right.}{\mathbb{E}_{t-1}\left\{F_{k, t} u_{c, t}\right\}}+\frac{\mathbb{E}_{t-1}\left\{F_{k, t} \nu_{t} u_{c, t}\right\}}{\mathbb{E}_{t-1}\left\{F_{k, t} u_{c, t}\right\}}}\left[\frac{\mathbb{E}_{t-1}\left\{k_{t-1} F_{k, t} u_{c, t}, \nu_{t}\right\}}{\mathbb{E}_{t-1}\left\{k_{t-1} F_{k, t} u_{c, t}\right\}}-\frac{\mathbb{E}_{t-1}\left\{k_{t-1} F_{k k, t} u_{c, t}, \nu_{t}\right\}}{\mathbb{E}_{t-1}\left\{k_{t-1} F_{k k, t} u_{c, t}\right\}}\right] \\
T_{t}^{i}=-\frac{\frac{\mathbb{E}_{t-1}\left\{\left[1+\left(1-\tau^{k}\right) F_{k, t}\right] u_{c, t}\left(\frac{\psi_{t}}{u_{c, t}}-\frac{\psi_{t-1}}{u_{c, t-1}}\right)\right\}}{\beta \mathbb{E}_{t-1}\left\{u_{c, t} F_{k, t}\right\}}}{\frac{\mathbb{E}_{t-1}\left\{F_{k, t} u_{c, t} \frac{\psi_{t}}{\left.u_{c, t}\right\}}\right.}{\mathbb{E}_{t-1}\left\{F_{k, t} u_{c, t}\right\}}+\frac{\mathbb{E}_{t-1}\left\{F_{k, t} \nu_{t} u_{c, t}\right\}}{\mathbb{E}_{t-1}\left\{F_{k, t} u_{c, t}\right\}}}
\end{gathered}
$$

and

$$
T_{t}^{b}=\frac{\frac{\frac{\nu_{2}, t-1}{\beta} \underline{M}_{k, t-1}-\frac{\nu_{1}, t-1}{\beta} \bar{M}_{k, t-1}}{\beta \mathbb{E}_{t-1}\left\{u_{c, t} F_{k, t}\right\}}}{\frac{\mathbb{E}_{t-1}\left\{F_{k, t} u_{c, t} \frac{\psi_{t}}{u_{c, t}}\right\}}{\mathbb{E}_{t-1}\left\{F_{k, t} u_{c, t}\right\}}+\frac{\mathbb{E}_{t-1}\left\{F_{k, t} \nu_{t} u_{c, t}\right\}}{\mathbb{E}_{t-1}\left\{F_{k, t} u_{c, t}\right\}}}
$$

This in turn shows that (28) holds.

\section{Proof of Proposition 1}


If $F(k, l, s)=A(s) k^{\alpha} l^{1-\alpha}$, then $k F_{k k, s}=(\alpha-1) F_{k, s}$ so that

$$
\frac{\operatorname{Cov}\left\{k F_{k k, s}, \nu_{s} \mid s_{-}\right\}}{\mathbb{E}\left\{k F_{k k, s} \mid s_{-}\right\}}=\frac{(\alpha-1) \operatorname{Cov}\left\{F_{k, s}, \nu_{s} \mid s_{-}\right\}}{(\alpha-1) \mathbb{E}\left\{F_{k, s} \mid s_{-}\right\}}=\frac{\operatorname{Cov}\left\{k F_{k, s}, \nu_{s} \mid s_{-}\right\}}{\mathbb{E}\left\{k F_{k, s} \mid s_{-}\right\}}
$$

By (28), this implies that $\tau^{k}=0$.

Since (28) applies from $t=1$ on, this shows that $\tau_{t}^{k}=0$ for all $t \geq 1$.

\section{Proof of Proposition 2}

I first prove the following lemma

Lemma 3 Consider $\left\{x_{n}, y_{n}, z_{n}\right\}_{1 \leq n \leq N} \in \mathbb{R}_{++}^{N}$, and probability distribution $\left\{p_{n}\right\}_{1 \leq n \leq N}$ with $p_{n}>0$ for all $n$. Assume that there exists $n$ and $n^{\prime}$ such that $z_{n} \neq z_{n^{\prime}}$. The following holds: (i) assume that $x_{n}<x_{n^{\prime}}$ if and only if $z_{n}>z_{n^{\prime}}$, then $\frac{\mathbb{E}\left\{x_{n} y_{n} z_{n}\right\}}{\mathbb{E}\left\{x_{n} y_{n}\right\}}<\frac{\mathbb{E}\left\{y_{n} z_{n}\right\}}{\mathbb{E}\left\{y_{n}\right\}}$; (ii) assume that $x_{n}<x_{n^{\prime}}$ if and only if $z_{n}<z_{n^{\prime}}$, then $\frac{\mathbb{E}\left\{x_{n} y_{n} z_{n}\right\}}{\mathbb{E}\left\{x_{n} y_{n}\right\}}>\frac{\mathbb{E}\left\{y_{n} z_{n}\right\}}{\mathbb{E}\left\{y_{n}\right\}}$.

Proof.

$$
\frac{\mathbb{E}\left\{x_{n} y_{n} z_{n}\right\}}{\mathbb{E}\left\{x_{n} y_{n}\right\}}<\frac{\mathbb{E}\left\{y_{n} z_{n}\right\}}{\mathbb{E}\left\{y_{n}\right\}}
$$

if and only if

$$
\mathbb{E}\left\{x_{n} y_{n} z_{n}\right\} \mathbb{E}\left\{y_{n}\right\}<\mathbb{E}\left\{y_{n} z_{n}\right\} \mathbb{E}\left\{x_{n} y_{n}\right\}
$$

if and only if

$$
\sum_{n, n^{\prime}} p_{n} p_{n^{\prime}} x_{n} y_{n} z_{n} y_{n^{\prime}}<\sum_{n, n^{\prime}} p_{n} p_{n^{\prime}} y_{n} z_{n} x_{n^{\prime}} y_{n^{\prime}}
$$

if and only if

$$
0<\sum_{n, n^{\prime}} p_{n} p_{n^{\prime}} y_{n} z_{n} y_{n^{\prime}}\left[x_{n^{\prime}}-x_{n}\right]
$$

if and only if

$$
0<\frac{1}{2} \sum_{n \neq n^{\prime}} p_{n} p_{n^{\prime}} y_{n} y_{n^{\prime}}\left[z_{n}-z_{n^{\prime}}\right]\left[x_{n^{\prime}}-x_{n}\right]
$$

which trivially proves claims (i) and (ii) in the lemma.

Assume $F$ is CES with elasticity of substitution $\sigma$ with Hicks neutral technology shocks:

$$
F(k, l)=A(s)\left[\alpha k^{\frac{\sigma-1}{\sigma}}+(1-\alpha) l^{\frac{\sigma-1}{\sigma}}\right]^{\frac{\sigma}{\sigma-1}}
$$

Then

$$
F_{k}(k, l)=\alpha A(s) k^{\frac{-1}{\sigma}}\left[\alpha k^{\frac{\sigma-1}{\sigma}}+(1-\alpha) l^{\frac{\sigma-1}{\sigma}}\right]^{\frac{1}{\sigma-1}}
$$

and

$$
-k F_{k k}(k, l)=\frac{\frac{1}{\sigma}}{\frac{\alpha}{1-\alpha}\left(\frac{k}{l}\right)^{\frac{\sigma-1}{\sigma}}+1} \alpha A(s) k^{\frac{-1}{\sigma}}\left[\alpha k^{\frac{\sigma-1}{\sigma}}+(1-\alpha) l^{\frac{\sigma-1}{\sigma}}\right]^{\frac{1}{\sigma-1}}
$$


so that

$$
-k F_{k k}(k, l)=\frac{\frac{1}{\sigma}}{\frac{\alpha}{1-\alpha}\left(\frac{k}{l}\right)^{\frac{\sigma-1}{\sigma}}+1} F_{k}(k, l)
$$

Proposition 2 now follows. Consider for example case (i). Then $\frac{\frac{1}{\sigma}}{\frac{\alpha}{1-\alpha}\left(\frac{k}{l_{s}}\right)^{\frac{\sigma-1}{\sigma}}+1}$ is a decreasing function of $\nu_{s}$. Lemma 3 shows that

$$
\frac{\mathbb{E}\left\{-k F_{k k, s}, \nu_{s} \mid s_{-}\right\}}{\mathbb{E}\left\{-k F_{k k, s} \mid s_{-}\right\}}<\frac{\mathbb{E}\left\{k F_{k, s}, \nu_{s} \mid s_{-}\right\}}{\mathbb{E}\left\{k F_{k, s} \mid s_{-}\right\}}
$$

which proves that $\tau^{k}>0$. Cases (ii), (iii) and (iv) in Proposition 2 can be proved along the same lines.

I then prove the second part of the proposition. If $F(k, l, s)=A(s) k^{\alpha} l^{1-\alpha}-\delta k$, then $k F_{k k, s}=$ $(\alpha-1)\left(F_{k, s}+\delta\right)$ so that

$$
\frac{\operatorname{Cov}\left\{k F_{k k, s}, \nu_{s} \mid s_{-}\right\}}{\mathbb{E}\left\{k F_{k k, s} \mid s_{-}\right\}}=\frac{(\alpha-1) \operatorname{Cov}\left\{F_{k, s}, \nu_{s} \mid s_{-}\right\}}{(\alpha-1) \delta+(\alpha-1) \mathbb{E}\left\{F_{k, s} \mid s_{-}\right\}}=\frac{\operatorname{Cov}\left\{k F_{k, s}, \nu_{s} \mid s_{-}\right\}}{\mathbb{E}\left\{k F_{k, s} \mid s_{-}\right\}+\delta}
$$

Hence

$$
\frac{\operatorname{Cov}\left\{k F_{k k, s}, \nu_{s} \mid s_{-}\right\}}{\mathbb{E}\left\{k F_{k k, s} \mid s_{-}\right\}}<\frac{\operatorname{Cov}\left\{k F_{k, s}, \nu_{s} \mid s_{-}\right\}}{\mathbb{E}\left\{k F_{k, s} \mid s_{-}\right\}}
$$

if and only if $\operatorname{Cov}\left\{k F_{k, s}, \nu_{s} \mid s_{-}\right\}>0$. This proves the second part of the proposition.

\section{Proof of Lemma 2}

It is clear that $\widetilde{V}$ is decreasing in $\widetilde{b}$. Since $\widetilde{V}$ is differentiable, this is equivalent to $\widetilde{V}_{b} \leq 0$. Since, $\beta \widetilde{V}_{b, t}=-\nu_{t}+\nu_{1, t}$, this proves that $\nu_{t}-\nu_{1, t} \geq 0$.

Under natural debt limits, (21) becomes

$$
\nu_{s-}=\mathbb{E}\left\{\nu_{s} \mid s_{-}\right\}+\nu_{1, s_{-}}
$$

which I can rewrite as

$$
\nu_{s-}-\nu_{1, s_{-}}=\mathbb{E}\left\{\nu_{s}-\nu_{1, s} \mid s_{-}\right\}+\mathbb{E}\left\{\nu_{1, s} \mid s_{-}\right\}
$$

This proves that $\left\{\widetilde{V}_{b, t}\right\}_{t \geq 1}$ is a nonnegative supermartingale. Therefore, the supermartingale convergence theorem (see Lòeve (1977)) asserts that $\widetilde{V}_{b, t}$ converges almost surely to a finite nonnegative random variable $\widetilde{V}_{b, \infty}$. Let $\mathbb{S}^{e}$ be the unique ergodic set of $\left\{s_{t}\right\}_{t \geq 0}$. Consider, for every $s \in \mathbb{S}^{e}$, the random sets $S^{s}=\left\{t, s_{t}=s\right\}$. Let $\phi^{s}(-1)=-1$ and for all $t \geq 0$, define the sequence of random numbers $\phi^{s}(t)=\inf \left\{t>\phi^{s}(t-1), s_{t}=s\right\}$. Since $\widetilde{V}$ is continuously differentiable and concave, this implies in turn that there are finite random variable $\widetilde{b}_{\infty, s}$ such that for every $s \in \mathbb{S}^{e}$, $\left\{\widetilde{b}_{\phi^{s}(t)}\right\}_{t \geq 0}$ converges to $\widetilde{b}_{\infty, s}$. Since policy functions in (15) are continuous, this implies that every point $\left\{\widetilde{b}^{s}\right\}_{s \in \mathbb{S}^{e}}$ in the support of $\left\{\widetilde{b}_{\infty, s}\right\}_{s \in \mathbb{S}^{e}}$ is such that for every states $s$ and $s_{-}$in the unique ergodic set of $\left\{s_{t}\right\}_{t \geq 0}, \widetilde{b}_{s}^{\prime}\left(\widetilde{b}^{s_{-}}, s_{-}\right)=\widetilde{b}^{s}$ and $\widetilde{V}_{b, s}\left(\widetilde{b}^{s}, s\right)=\widetilde{V}_{b, s_{-}}\left(\widetilde{b}^{s_{-}}, s_{-}\right)$. This implies that for starting at such a point $\left(\widetilde{b}^{s}, s\right)$, the planner is able to implement the optimal complete markets allocation. 
By Assumption 1, this is only possible if $\widetilde{b}^{s}=-\underline{M}_{s}^{n}$ for all $s$. This proves Lemma 2 .

\section{Proof of Proposition 3}

If $F(k, l, s)=A(s) k^{\alpha} l^{1-\alpha}$, then $k F_{k k, s}=(\alpha-1) F_{k, s}$ so that

$$
\frac{\operatorname{Cov}\left\{k F_{k k, s} u_{c, s}, \nu_{s} \mid s_{-}\right\}}{\mathbb{E}\left\{k F_{k k, s} u_{c, s} \mid s_{-}\right\}}=\frac{(\alpha-1) \operatorname{Cov}\left\{F_{k, s} u_{c, s}, \nu_{s} \mid s_{-}\right\}}{(\alpha-1) \mathbb{E}\left\{F_{k, s} u_{c, s} \mid s_{-}\right\}}=\frac{\operatorname{Cov}\left\{k F_{k, s} u_{c, s}, \nu_{s} \mid s_{-}\right\}}{\mathbb{E}\left\{k F_{k, s} u_{c, s} \mid s_{-}\right\}}
$$

\section{Proof of Proposition 4}

The proof follows closely Zhu (1992). More details can be found there.

Note that $T_{2, t}>0$ if and only if

$$
\frac{\mathbb{E}_{t-1}\left\{\left[1+\left(1-\tau^{k}\right) F_{k, t}\right] u_{c, t} \frac{\psi_{t}}{u_{c, t}}\right\}}{\mathbb{E}_{t-1}\left\{\left[1+\left(1-\tau^{k}\right) F_{k, t}\right] u_{c, t}\right\}}>\frac{\psi_{t-1}}{u_{c, t-1}}
$$

$T_{2, t}<0$ if and only if

$$
\frac{\mathbb{E}_{t-1}\left\{\left[1+\left(1-\tau^{k}\right) F_{k, t}\right] u_{c, t} \frac{\psi_{t}}{u_{c, t}}\right\}}{\mathbb{E}_{t-1}\left\{\left[1+\left(1-\tau^{k}\right) F_{k, t}\right] u_{c, t}\right\}}<\frac{\psi_{t-1}}{u_{c, t-1}}
$$

and $T_{2, t}=0$ if and only if

$$
\frac{\mathbb{E}_{t-1}\left\{\left[1+\left(1-\tau^{k}\right) F_{k, t}\right] u_{c, t} \frac{\psi_{t}}{u_{c, t}}\right\}}{\mathbb{E}_{t-1}\left\{\left[1+\left(1-\tau^{k}\right) F_{k, t}\right] u_{c, t}\right\}}=\frac{\psi_{t-1}}{u_{c, t-1}}
$$

Let me denote $\left[1+\left(1-\tau^{k}\right) F_{k, t}\right] u_{c, t}$ by $K_{t}$ and $\frac{\psi_{t}}{u_{c, t}}$ by $\xi_{t}$. Since policy functions in (10) are continuous, $K_{t}$ and $\xi_{t}$ are continuous functions $K\left(x_{t}\right)$ and $\xi\left(x_{t}\right)$ of $x_{t}=\left\{k_{t}, \tilde{b}_{t}, u_{c, t}, s_{t}\right\}$. Call $\pi\left(x^{\prime}, x\right)$ the transition function.

Let $\Upsilon$ be the operator mapping the space $\digamma$ of continuous functions of $x$ into itself, defined by

$$
\Upsilon(f)(x) \equiv \frac{\int f\left(x^{\prime}\right) K\left(x^{\prime}\right) \pi\left(x^{\prime}, x\right)}{\int K\left(x^{\prime}\right) \pi\left(x^{\prime}, x\right)}
$$

Therefore, $T_{2}(x)>0$ if and only if $\Upsilon(\xi)(x)>\xi(x), T_{2}(x)<0$ if and only if $\Upsilon(\xi)(x)<\xi(x)$ and $T_{2}(x)=0$ if and only if $\Upsilon(\xi)(x)=\xi(x)$. Thus the sign of $T_{2}$ is entirely determined by the sign of $\Upsilon(\xi)-\xi$

Suppose $P^{\infty}\{\Upsilon(\xi)(x) \leq \xi(x)\}=1$. Let $\underline{\xi} \equiv \max \left\{\xi, P^{\infty}\{\xi(x) \geq \xi\}=1\right\}$. Define $A_{t}=\{x, \xi(x) \geq$ $\left.\Upsilon^{t} \xi(x)\right\}, B_{t}=\left\{x, \operatorname{Pr}\left\{\xi\left(x_{t}\right) \geq \underline{\xi} \mid x_{0}=x\right\}=1\right\}, A=\cap_{t=0}^{\infty} A_{t}$ and $B=\cap_{t=0}^{\infty} B_{t}$. Then $A_{t}, B_{t}, A$ and $B$ are closed, and $P^{\infty}\left\{A_{t}\right\}=P^{\infty}\left\{B_{t}\right\}=1$. Hence $A \cap B$ is closed and $P^{\infty}\{A \cap B\}=1$. By definition of $\underline{\xi}$, there exists $x \in A \cap B$ such that $\xi(x)=\underline{\xi}$. This implies $\operatorname{Pr}\left\{\xi\left(x_{t}\right)=\underline{\xi} \mid x_{0}=x\right\}=1$. Using the ergodicity of $x_{t}$,

$$
P^{\infty}\{\xi(x)=\underline{\xi}\}=\lim _{t \rightarrow \infty} \operatorname{Pr}\left\{\xi\left(x_{t}\right)=\underline{\xi} \mid x_{0}=x\right\}=1
$$

Hence $P^{\infty}\{\xi(x)=\underline{\xi}\}=1$. Similarly $P^{\infty}\{\Upsilon(\xi)(x) \geq \xi(x)\}=1$ implies $P^{\infty}\{\xi(x)=\bar{\xi}\}=1$ where 
$\bar{\xi} \equiv \inf \left\{\xi, P^{\infty}\{\xi(x) \leq \xi\}=1\right\}$. This proves Proposition 4 .

\section{Proof of Proposition 5}

Consider the complete markets allocation $\left\{k_{c}, l_{c}, \widetilde{b}_{c}^{\prime}\right\}$ in state $\left(\widetilde{b}, s_{-}\right)$. Labor $l_{c}$ and net government liabilities in the end of the period $\widetilde{b}_{c}^{\prime}$ are constant across states of the world $s$. Define $X_{s} \equiv \frac{1}{\beta} \widetilde{b}+g_{s}-\widetilde{b}_{c}^{\prime}$.

Consider next the incomplete markets environment. Denote by $R\left(k, l_{s}\right) \equiv l_{s} F_{l, s}+l_{s} H_{l, s}$ the revenues from labor taxation in state $s$. Set $\tau^{k}=0$ and solve, for a given $k_{g}$, the following system in $\left\{k, l_{s}\right\}$.

$$
\begin{aligned}
\mathbb{E}\left\{R\left(k, l_{s}\right) \mid s_{-}\right\} & =\mathbb{E}\left\{X_{s} \mid s_{-}\right\} \\
\left(F_{k}\left(k, l_{s}\right)-r\right)+\frac{R\left(k, l_{s}\right)}{k_{g}} & =\frac{X_{s}}{k_{g}}, \quad \forall s \in \mathbb{S}
\end{aligned}
$$

Note that if (50) holds and $\left|k_{g}\right|<\infty$, then (49) is equivalent to $\mathbb{E}\left\{F_{k}\left(k, l_{s}\right) \mid s_{-}\right\}=r$. If (50) holds and $\left|k_{g}\right|=\infty$, then $\mathbb{E}\left\{F_{k}\left(k, l_{s}\right) \mid s_{-}\right\}=r$ holds automatically.

Denote by $\left\{k\left(k_{g}\right), l_{s}\left(k_{g}\right)\right\}$ the solution: together with $\widetilde{b}_{c, s}^{\prime}\left(k_{g}\right) \equiv \widetilde{b}_{c}^{\prime}$ for all $s$, the variables $\left\{k\left(k_{g}\right), l_{s}\left(k_{g}\right), \widetilde{b}_{c, s}^{\prime}\right\}$ satisfy the constraints in (15). Then

$$
\lim _{k_{g} \rightarrow \infty}\left\{k\left(k_{g}\right), l_{s}\left(k_{g}\right)\right\}=\lim _{k_{g} \rightarrow-\infty}\left\{k\left(k_{g}\right), l_{s}\left(k_{g}\right)\right\}=\left\{k_{c}, l_{c}\right\}
$$

Therefore, by choosing $k_{g}$ large and picking $\left\{k\left(k_{g}\right), l_{s}\left(k_{g}\right), \widetilde{b}_{c, s}^{\prime}\right\}$, the government can approximate as well as desired the complete markets allocation in state $\left(\widetilde{b}, s_{-}\right)$. By doing this in every state and date, the government can therefore perfectly approximate the complete markets allocation. This proves proposition 5 . 


\section{Figures and Tables}

Table 1: Optimal capital ownership (as a fraction of $\mathbf{k}$ ) in the quasi-linear model

$\begin{array}{lccc} & \text { Government shocks } & \text { Productivity shocks } & \begin{array}{c}\text { Government and productivity } \\ \text { shocks }\end{array} \\ \text { Period length }=1 \text { year } & \text { infinity } & -295 \% & -295 \% \\ \text { Period length }=5 \text { years } & \text { infinity } & -59 \% & -59 \%\end{array}$

Table 2: Summary statistics in the general model

\begin{tabular}{lcc}
\hline & Period length = 1 year & Period length $=5$ years \\
mean of labor taxes & $26.2 \%$ & $5.1 \%$ \\
per period std of labor taxes (\% of mean) & 0.62 \\
per period autocorrelation of labor taxes & $-4.8 \%$ \\
mean of capital taxes & 0.72 & 0.94 \\
per period std of capital taxes & -0.06 & 0.10 \\
per year autocorrelation of capital taxes & 0.03
\end{tabular}
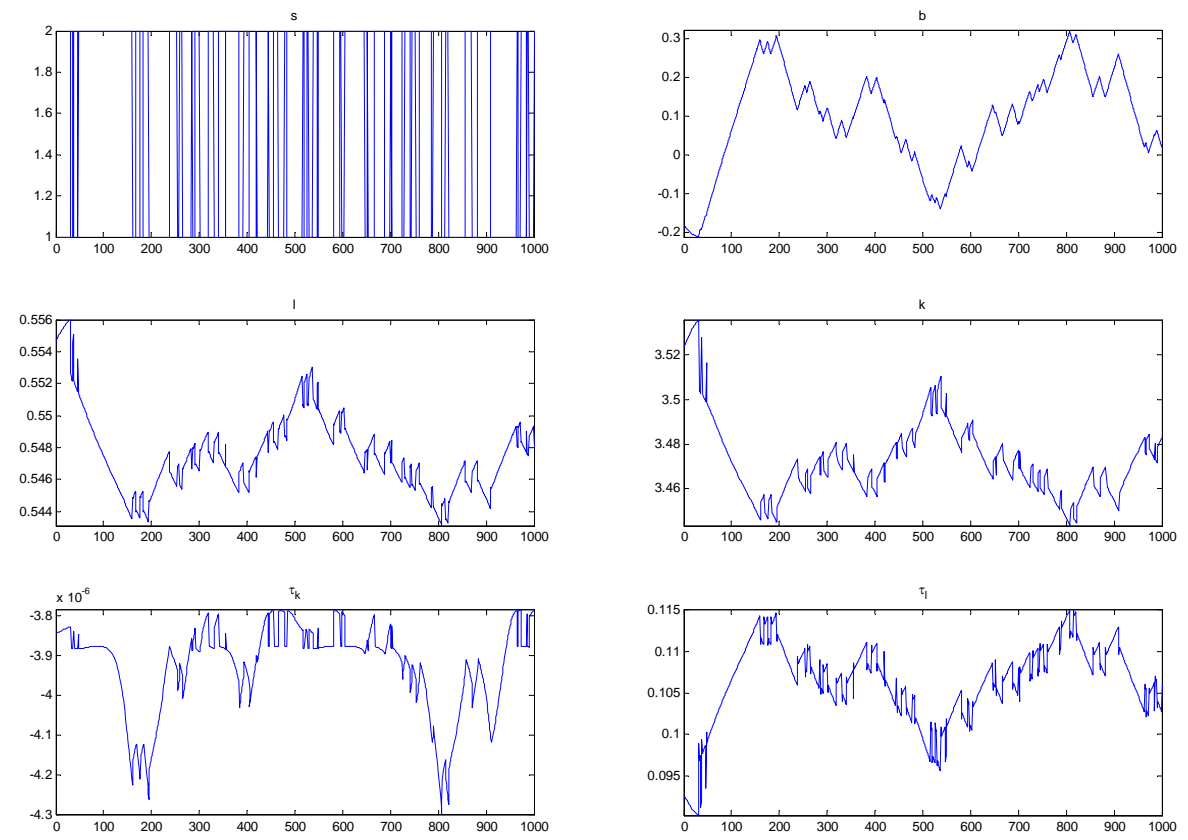

Figure 1: A typical path, quasi-linear preferences, government expenditure shocks. 

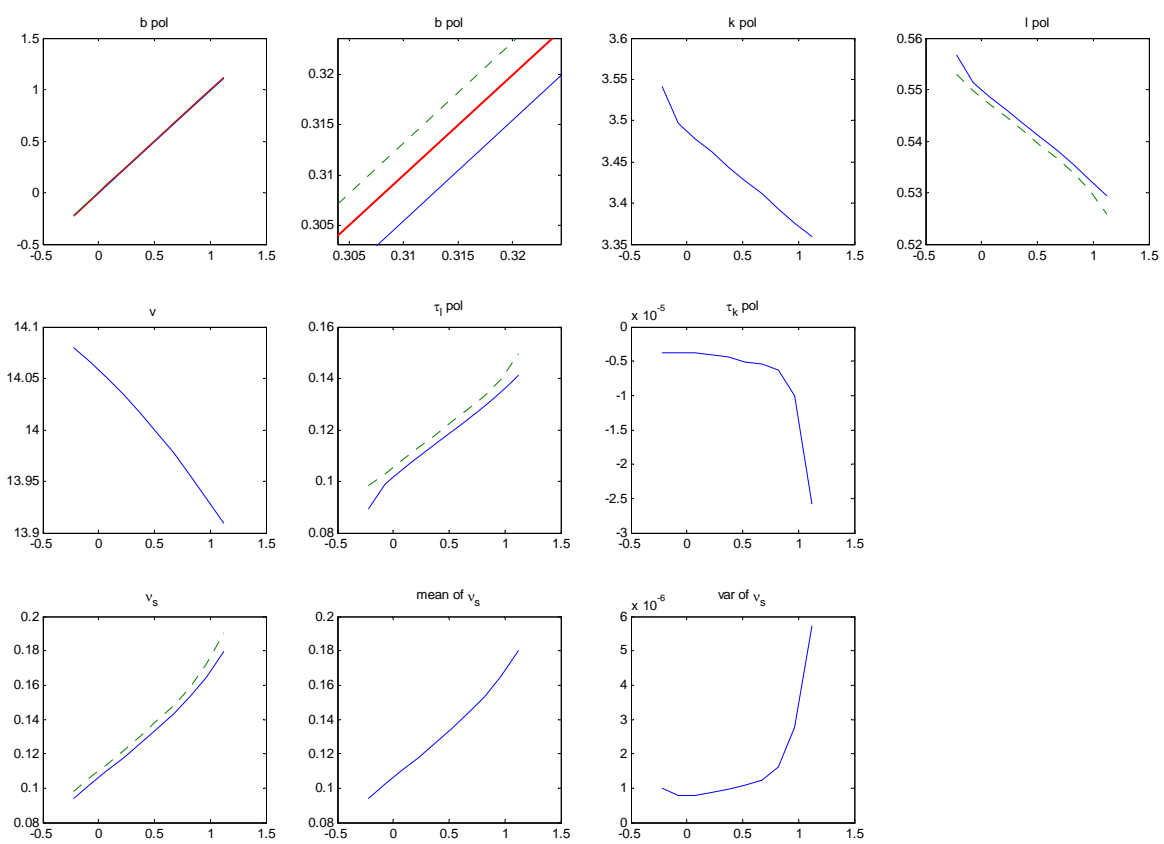

Figure 2: Policy functions, quasi-linear preferences, government expenditure shocks, $s_{-}$low.
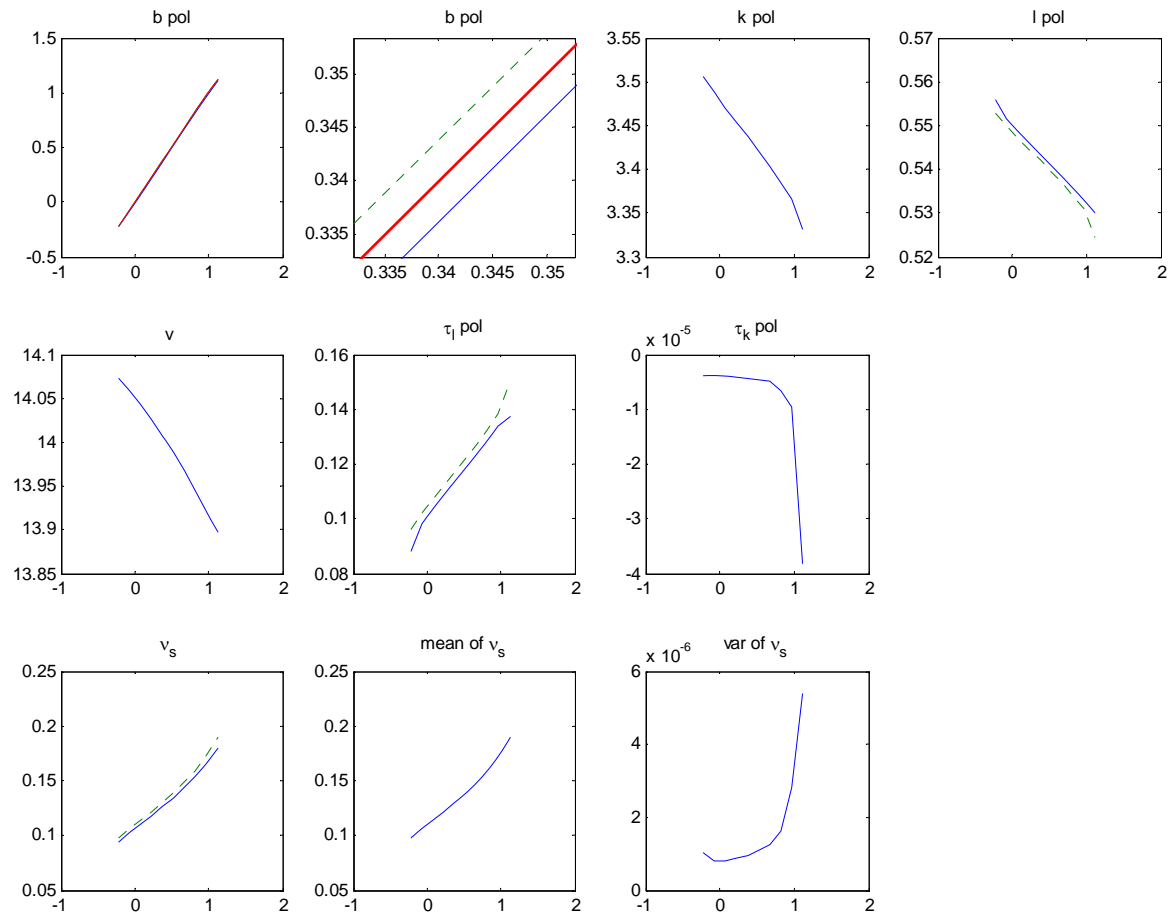

Figure 3: Policy functions, quasi-linear preferences, goverment expenditure shocks, $s_{-}$high. 

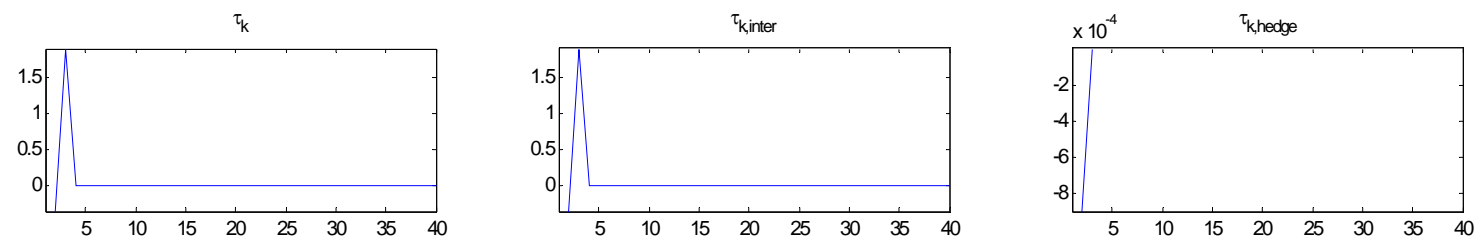

$\tau_{1}$
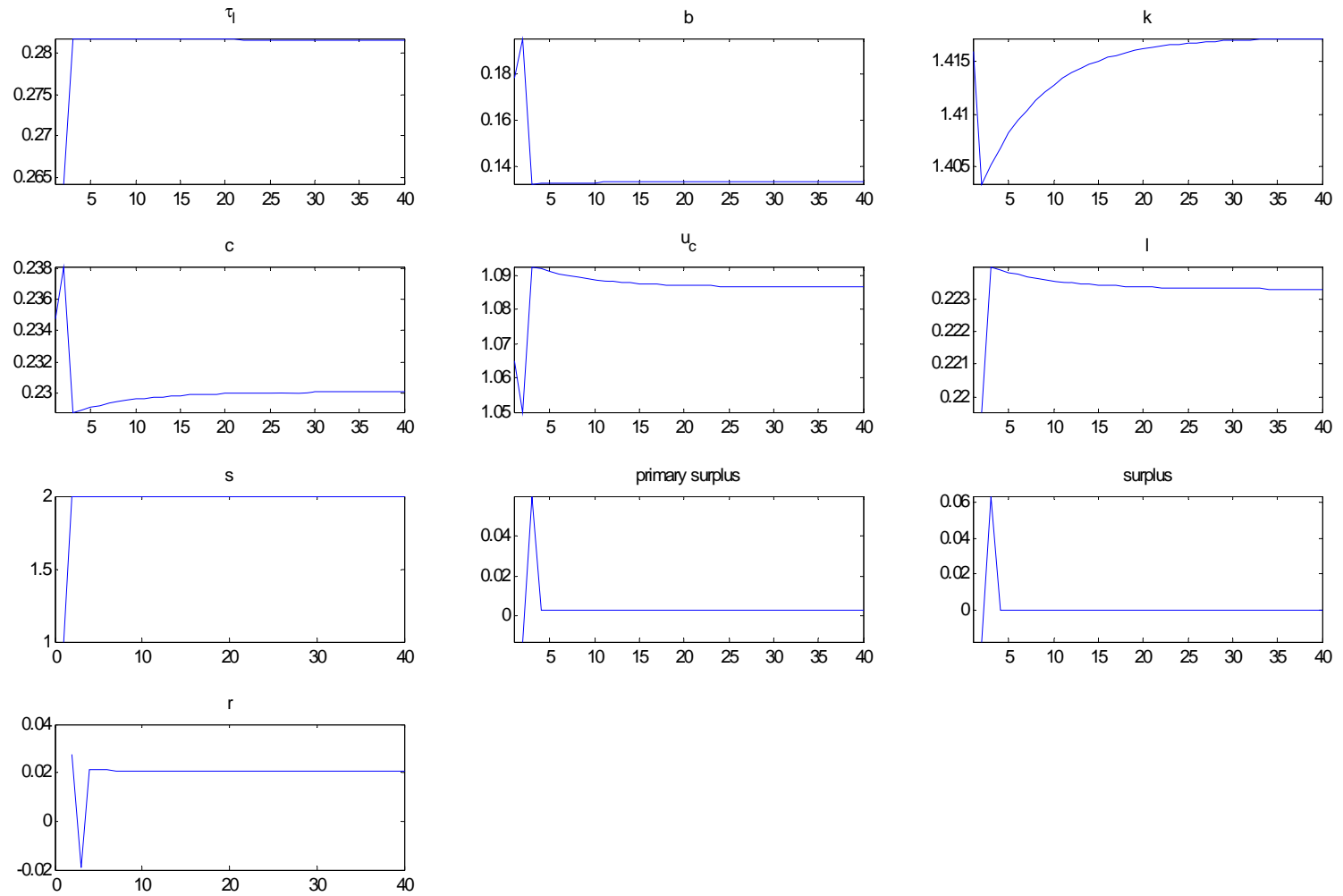

Figure 4: Impulse responses, high permanent government expenditure shock 

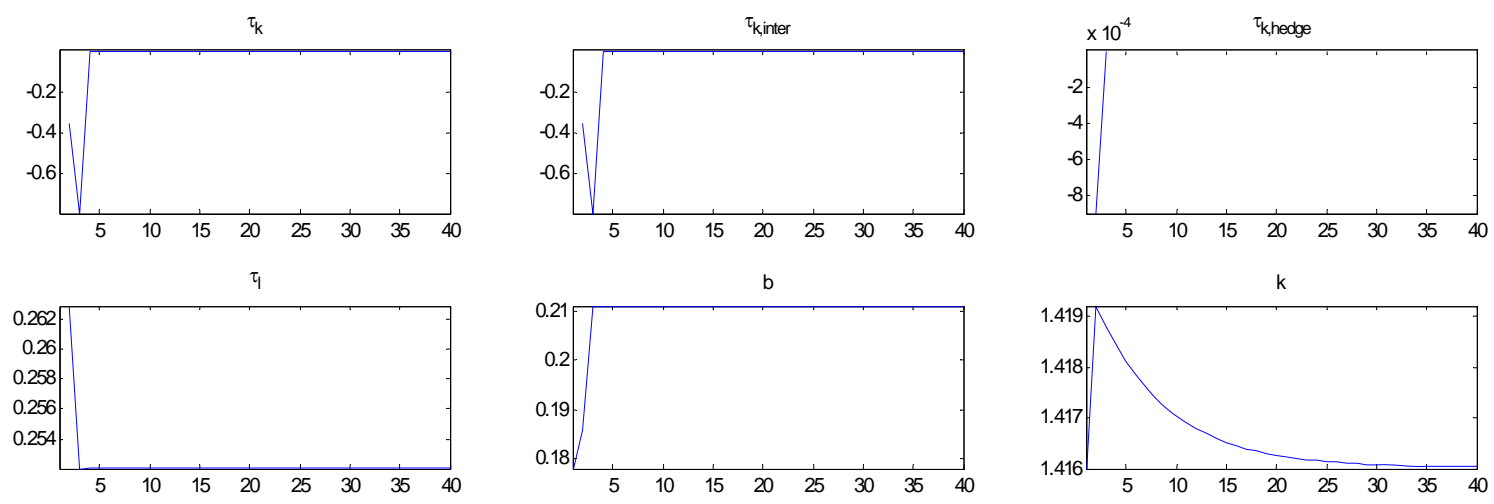

c
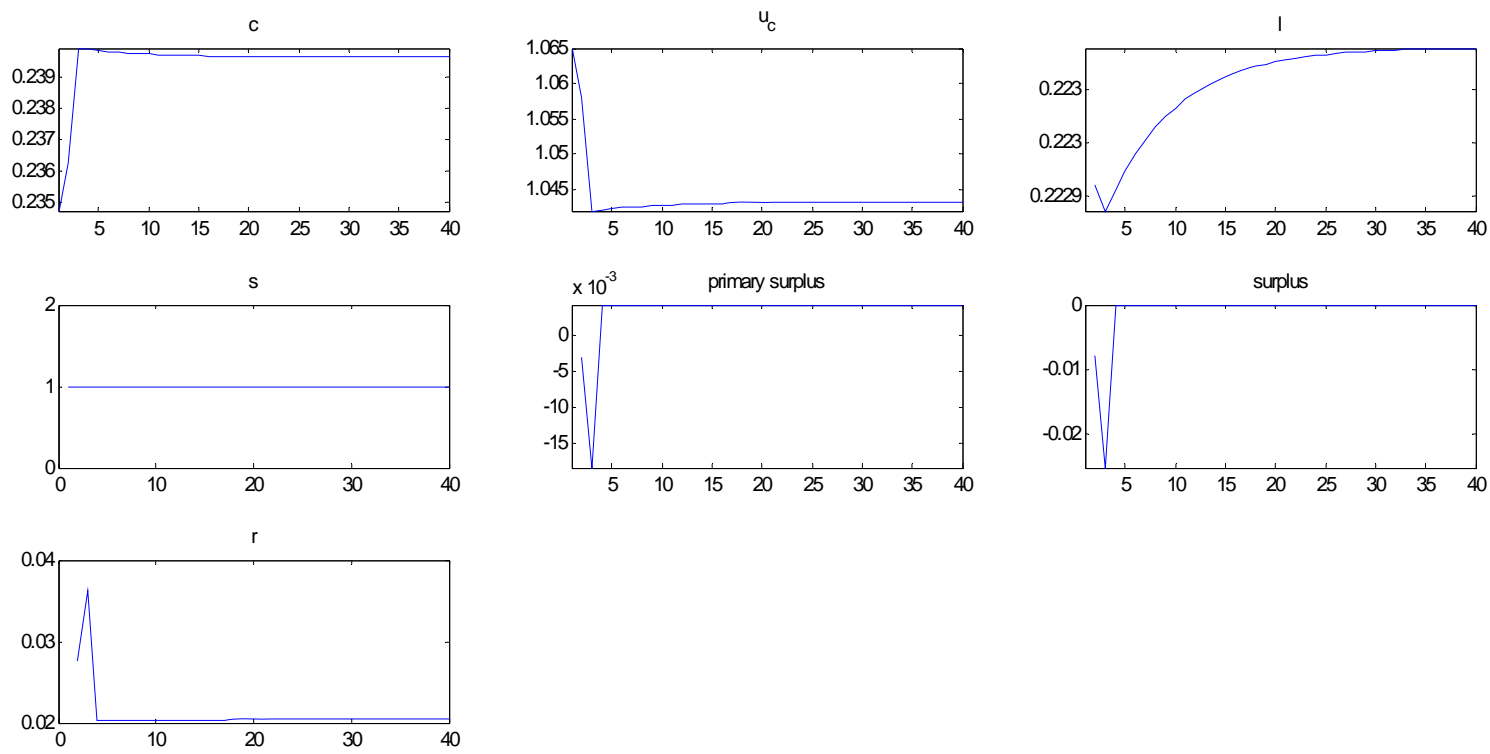

Figure 5: Impulse responses, low permanent government expenditure shock 

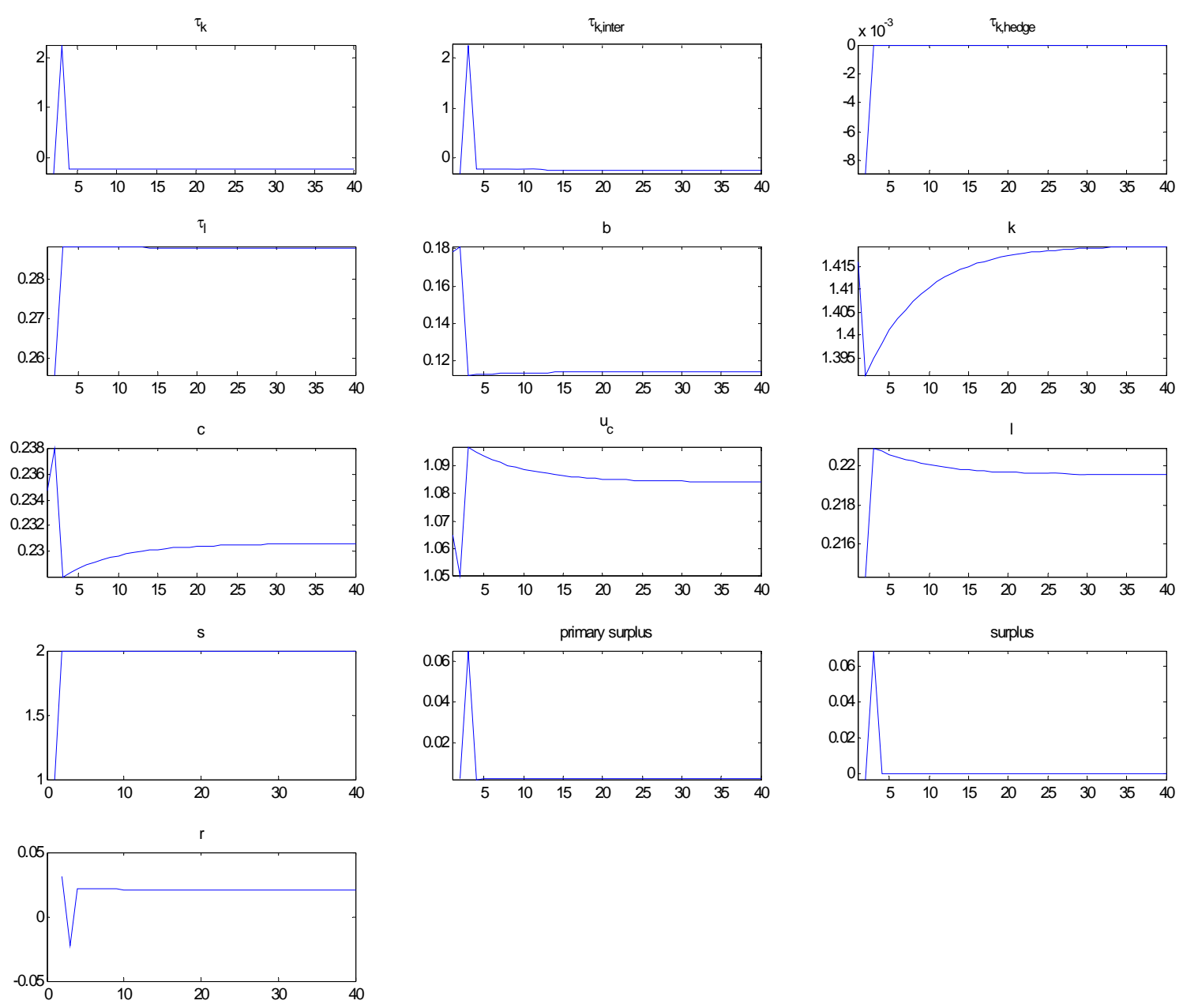

Figure 6: Impulse responses, low permanent technology shock 

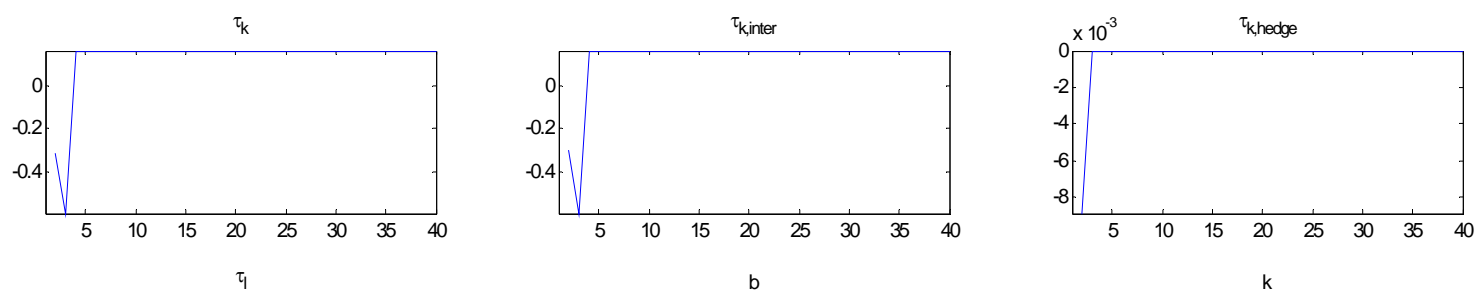

$\tau_{1}$
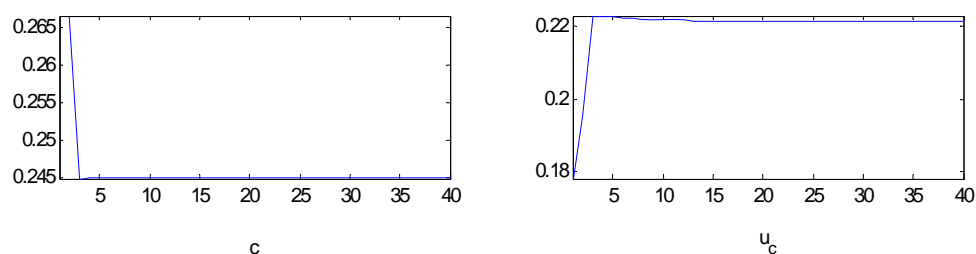

k

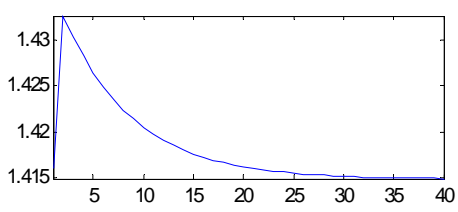

c
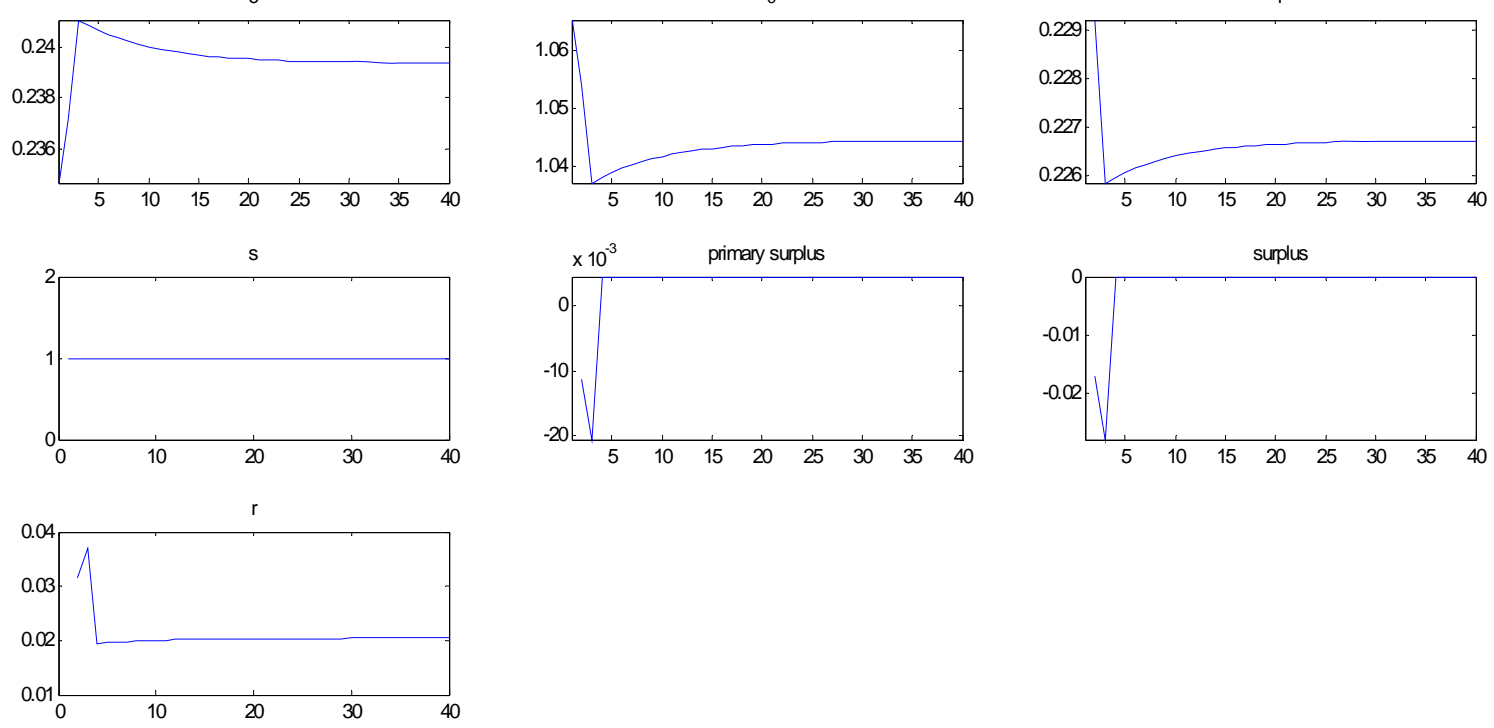

Figure 7: Impulse responses, high permanent technology shock 

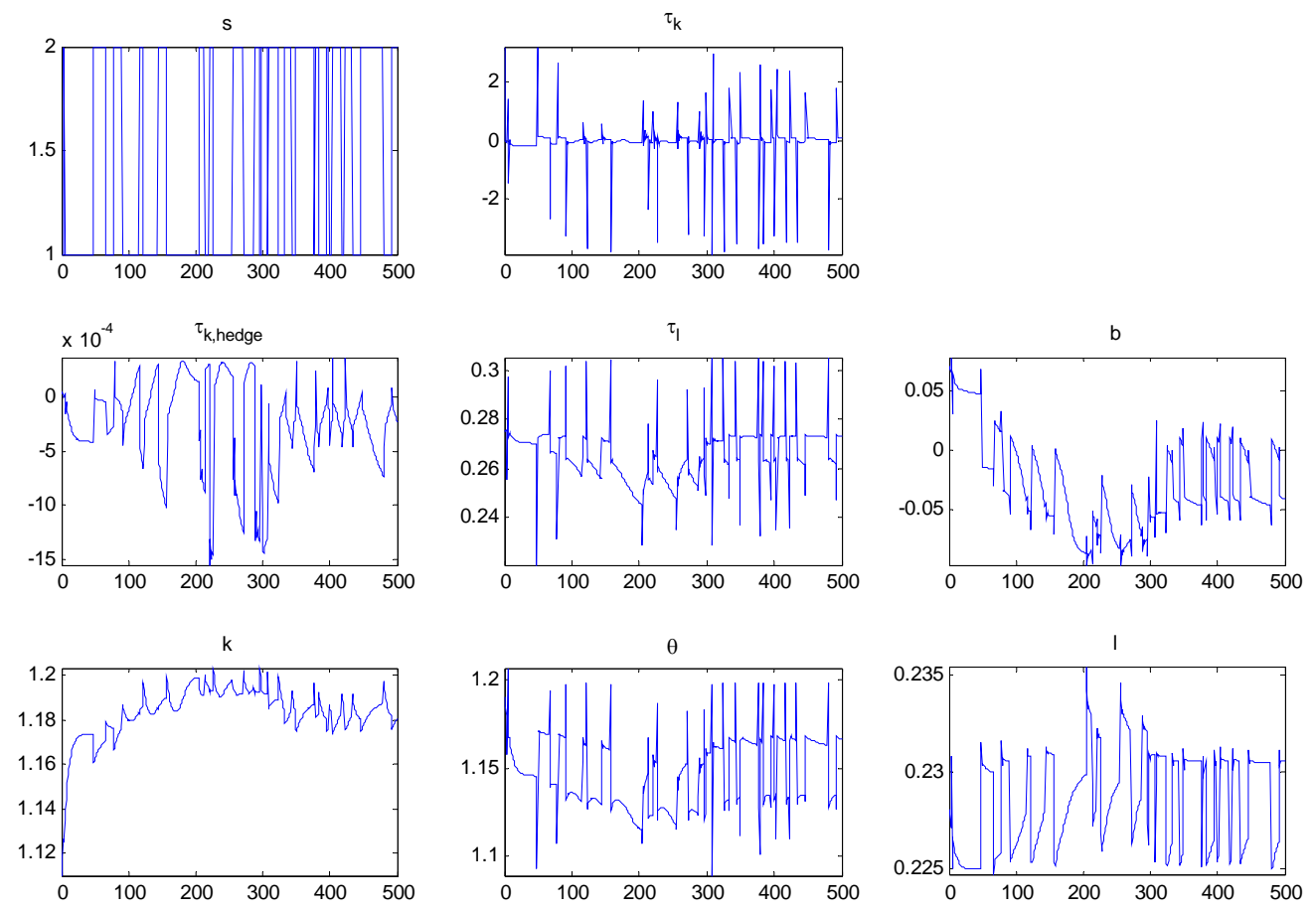

Figure 8: A typical path: government expenditure shocks, one year period length
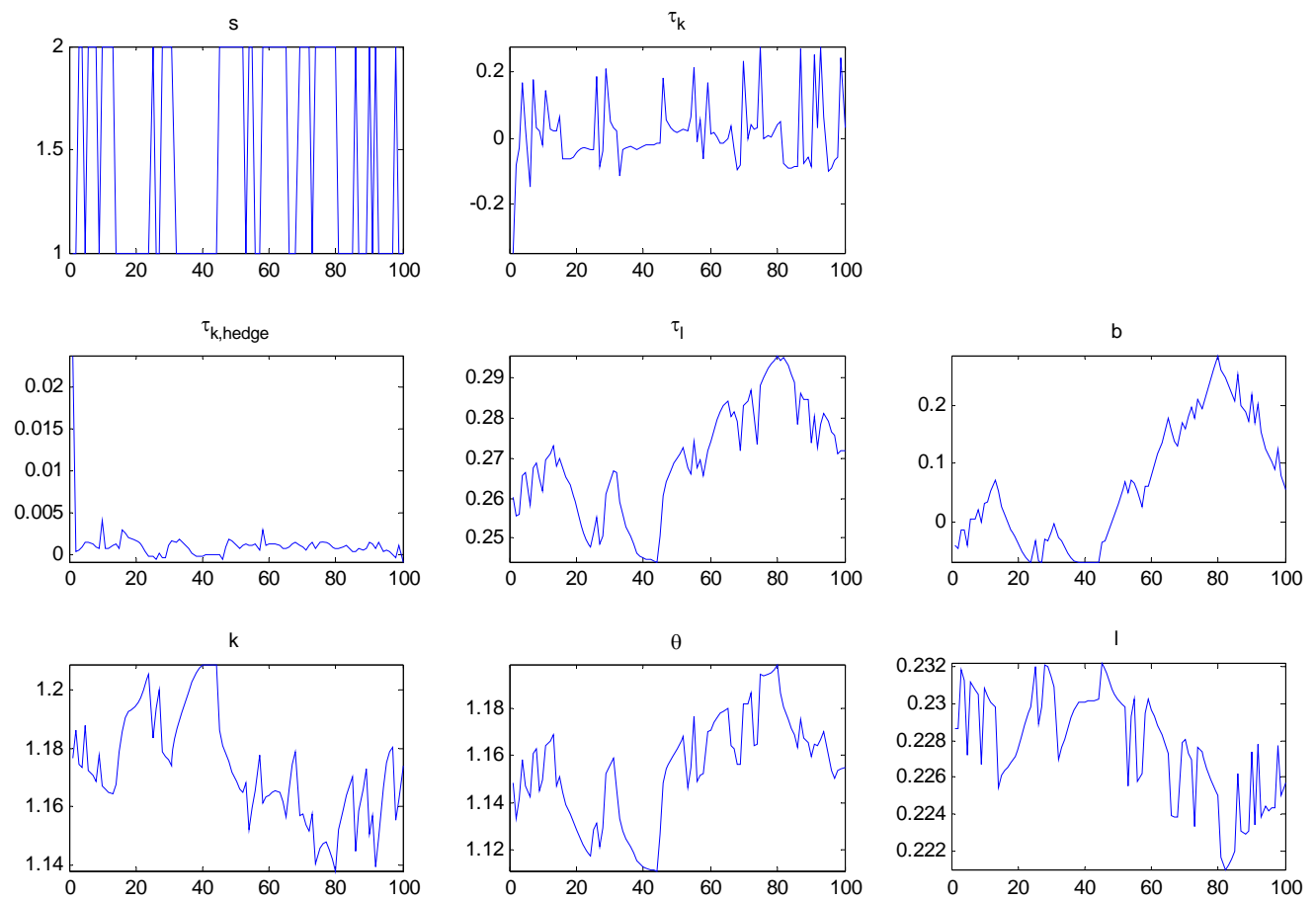

Figure 9: A typical path: government expenditure shocks, five years period length 


\section{References}

[1] Aiyagari, S.R, Marcet, A., Sargent, T.J, and Juha Seppälä (2002): "Optimal Taxation without State Contingent Debt", Journal of Political Economy, 110, 1220-1254.

[2] Angeletos, George-Marios (2002): "Fiscal Policy with Non-Contingent Debt and the Optimal Maturity Structure", Quarterly Journal of Economics, 117, 1105-1131.

[3] Atkeson, A., Chari, V.V., and Patrick J. Kehoe (1999): "Taxing Capital Income: A Bad Idea", Federal Reserve Bank of Minneapolis Quarterly Review, 23, 3-17..

[4] Atkinson, A.B and Joseph E. Stiglitz (1972): "The Structure of Indirect Taxation and Economic Efficiency", Journal of Public Economics, 1, 97-119.

[5] Barro, Robert J. (1979): "On the Determination of Public Debt", Journal of Political Economy, 87, 940-971.

[6] Bohn, Henning (1990): "Tax Smoothing with Financial Instruments", American Economic Review, 80, 1217-1230.

[7] Buera, F. and Juan P. Nicolini (2004): "Optimal Maturity Structure of Government Debt without State Contingent Bonds", Journal of Monetary Economics, 51, 531-554.

[8] Chamley, Christophe (1986): "Optimal Taxation of Capital Income in General Equilibrium with Infinite Lives", Econometrica, 54, 607-622.

[9] Chari, V.V., Christiano, L.J. and Patrick J. Kehoe (1994): "Optimal Fiscal Policy in a Business Cycle Model", Journal of Political Economy, 102, 617-652.

[10] Farhi, E. and Ivan Werning (2005): "The Optimal Maturity Structure of Government Debt when Markets are Incomplete", mimeo MIT.

[11] Judd, Kenneth L. (1985): "Redistributive Taxation in a Simple Perfect Foresight Model", Journal of Public Economics, 28, 59-83.

[12] Judd, Kenneth L. (1992): "Optimal Taxation in Dynamic Economies: Theory and Evidence", mimeo.

[13] Loève, M. (1977): "Probability Theory II", Springer Verlag, 4th edition.

[14] Lucas, R. and Nancy Stokey (1983): "Optimal Fiscal and Monetary Policy in an Economy without Capital", Journal of Monetary Economics, 12, 55-93.

[15] Ramsey, Frank P. (1927): "A Contribution to the Theory of Taxation", Economic Journal, XLVIII, 47-61. 
[16] Stiglitz, Joseph E. (1969): "The Effects of Income, Wealth, and Capital Gains Taxation on Risk-Taking", Quarterly Journal of Economics, 83, 263-283.

[17] Werning, Ivan (2005): "Tax Smoothing with Incomplete Markets", MIT mimeo.

[18] Zhu, Xiaodong (1992): "Optimal Fiscal Policy in a Stochastic Growth Model", Journal of Economic Theory, 58, 250-289. 